\title{
Multimodel GCM-RCM Ensemble-Based Projections of Temperature and Precipitation over West Africa for the Early 21 st Century
}

\author{
I. Diallo, ${ }^{1}$ M. B. Sylla, ${ }^{2}$ F. Giorgi, ${ }^{2}$ A. T. Gaye, ${ }^{1}$ and M. Camara ${ }^{3}$ \\ ${ }^{1}$ Laboratory for Atmospheric Physics-Simeon Fongang (LPAF), Polytechnic School, Cheikh Anta Diop University, P.O. Box 5085, \\ Dakar-Fann, Dakar, Senegal \\ ${ }^{2}$ Earth System Physics (ESP) Section, International Centre for Theoretical Physics (ICTP), 34151 Trieste, Italy \\ ${ }^{3}$ Department of Physics, UFR of Sciences and Technologies, University of Ziguinchor, 523 Ziguinchor, Senegal
}

Correspondence should be addressed to I. Diallo, ismaila1.diallo@ucad.edu.sn

Received 14 May 2011; Revised 6 September 2011; Accepted 21 November 2011

Academic Editor: Alessandra Giannini

Copyright @ 2012 I. Diallo et al. This is an open access article distributed under the Creative Commons Attribution License, which permits unrestricted use, distribution, and reproduction in any medium, provided the original work is properly cited.

\begin{abstract}
Reliable climate change scenarios are critical for West Africa, whose economy relies mostly on agriculture and, in this regard, multimodel ensembles are believed to provide the most robust climate change information. Toward this end, we analyze and intercompare the performance of a set of four regional climate models (RCMs) driven by two global climate models (GCMs) (for a total of 4 different GCM-RCM pairs) in simulating present day and future climate over West Africa. The results show that the individual RCM members as well as their ensemble employing the same driving fields exhibit different biases and show mixed results in terms of outperforming the GCM simulation of seasonal temperature and precipitation, indicating a substantial sensitivity of RCMs to regional and local processes. These biases are reduced and GCM simulations improved upon by averaging all four RCM simulations, suggesting that multi-model RCM ensembles based on different driving GCMs help to compensate systematic errors from both the nested and the driving models. This confirms the importance of the multi-model approach for improving robustness of climate change projections. Illustrative examples of such ensemble reveal that the western Sahel undergoes substantial drying in future climate projections mostly due to a decrease in peak monsoon rainfall.
\end{abstract}

\section{Introduction}

Addressing climate change over West Africa is a great challenge for understanding the effects of greenhouse gas (GHG) warming at local and regional scales. Such assessment is critical because Africa is mostly covered by semiarid regions known for their unreliable rainfall regime which is highly variable on intraseasonal, interannual and interdecadal time scales [1-3]. This variability often translates into severe droughts and floods [4] and may substantially impact food security and water resources. Therefore, changes in future climate may pose significant threats to the region especially in resource poor contexts where agriculture is a prominent instrument for enhancing food security, and adaptive capacity is relatively low [5].
The production of accurate and reliable climate change scenarios for the West African continent is therefore a major issue. In this region, climate change projections have been often derived using global climate models (GCMs) $[6,7]$. However, despite the significant progress in climate modeling, projections over West Africa are limited by at least two factors. First, the West African monsoon precipitation response to anthropogenic climate change is uncertain $[8,9]$ because the spread among the GCM projections is quite large $[1,10,11]$. Second, the typical grid box of GCMs (in the range of $100-400 \mathrm{~km}$ ) is not suitable to account for land surface heterogeneity such as vegetation variations, complex topography, and coastlines, which are important aspects of the physical response governing the local and regional climate change signal $[12,13]$. 
Regional Climate Models (RCMs) can be used to dynamically downscale GCMs output in order to account for finescale forcings and to provide climate change information at the local and regional level needed for impact assessments [14-16]. Earlier studies have shown that RCM can adequately represent the West African monsoon climatology [17-20] and its variability [21-23], and can be useful to understand the interactions between the different dynamical circulations affecting the monsoon [2,24-27]. RCMs have also been used to construct climate change scenarios for the early and late 21st century [28-30], (Sylla et al. 2011b) to study the influence of land-use changes and monsoon circulation dynamics on future climate $[4,31]$ and the responses of hydrology and crop models to GHGs warming [32, 33].

In the impact assessment phase, a key problem is that both the GCMs and RCMs results suffer from the existence of substantial uncertainties of different sources [34-36]. Such sources include, for example, anthropogenic emissions; large-scale and regional/local-scale changes that are sensitive to the model parameterisations and internal dynamics [37]. Therefore, a necessary approach to the generation of climate projections and the characterization of related uncertainties is to use multi-model ensemble experiments [35]. In fact, Giorgi and Coppola [38] noted that a minimum of four to five models is needed to obtain robust regional precipitation change estimates. The ensemble approach has been recently used over West Africa by Paeth et al. [30] employing a set of nine RCMs.

In this paper, we present a multi-model ensemble analysis of climate change projections over West Africa including four RCMs driven by 2 different GCMs, for a total of four different GCM-RCM pairs (see Table 1). We first examine and intercompare the performance and projected changes of the individual driving GCMs and nested RCMs, and then we investigate how different types of subensembles (ensemble of RCMs driven by same GCMs and ensemble of RCMs driven by different GCMs) can improve the robustness of the climate change signal. The sample of GCMs/RCMs pairs in the ensemble is relatively small (2-4 models), so that this study should be considered as providing illustrative methodological examples rather than scenarios over the region for application to impact and adaptation studies. The next section begins with the RCMs description, the boundary forcing (GCMs) and observation datasets used for the baseline validation.

\section{Models Description and Observation Datasets}

Ensemble of RCM experiments have been performed for different African domains encompassing the full West Africa AMMA region [45] (Figure 1) as part of the ENSEMBLES project [46]. A set of ten RCMs employing the same and different GCMs boundary conditions forced by the A1B GHGs scenario are available over West Africa for both present day and future climate conditions. For these experiments, the boundaries were placed well outside the region of interest and this has allowed the RCMs to develop their own dynamics in the interior domain. While the model domain might affect the RCM simulations, the large domain size employed by the models should minimize this effect. The main purpose of this study is to assess the present-day simulation but also the mid-term future projections over West Africa. In this regards, we consider only the four RCM simulations which cover the full periods of 1981-2000 (present day) and 2031-2050 (future). They are summarized in Table 1 along with their driving GCMs and references. Note that in this set, two RCMs are driven by ECHAM5, and the other two are forced by HadCM3. Both ECHAM5 and HadCM3 realistically simulate most of the features of the WAM circulation including the zonal wind profile which most GCMs usually fail to reproduce $[4,47]$. Each of the GCMs and the RCMs was a single run. The provision of the same and different GCMs boundary forcing makes it possible to evaluate not only the internal dynamics of each of the regional configurations but also the role of the large-scale conditions. We should emphasize that these RCMs were first driven by ERAInterim reanalysis as it is usually the case before applying them for climate change studies $[14,42]$. However, these simulations are not analyzed here. We also stress that the simulations analyzed here were the only ones including the full 20-year present day and future periods selected.

As stated above, two periods of 20 years are considered: the present-day (reference: 1981-2000) and the future (A1B: 2031-2050). For the present-day climate, simulated precipitation is compared to the observational datasets: GPCP (Global Precipitation Climatology Project; $2.5^{\circ} \times 2.5^{\circ}$ resolution; [48]), CRU (Climate Research Unit, land only, $0.5^{\circ} \times$ $0.5^{\circ}$ resolution; [49]), CMAP (Climate Prediction Center Merged Analysis of Precipitation, $2.5^{\circ} \times 2.5^{\circ}$; [50]) and GPCC (Global Precipitation Climatology Centre, $1^{\circ} \times 1^{\circ}$ resolution; [51]). The simulated 2-meter temperature is validated against the CRU observation, ERA-40 reanalysis $\left(2.5^{\circ} \times\right.$ $2.5^{\circ}$ resolution; [52]), the National Centers for Environment Prediction/National Center for Atmospheric Research $(\mathrm{NCEP} / \mathrm{NCAR})$ reanalysis II $\left(2.5^{\circ} \times 2.5^{\circ}\right.$ resolution; [53] $)$ and the ERA-Interim reanalysis $\left(1.5^{\circ} \times 1.5^{\circ}\right.$ resolution; $\left.[54,55]\right)$. The wind field and specific humidity are also compared with the reanalysis of NCEP/NCAR II, ERA-40, and ERA-Interim. We only consider the June-September (JJAS) period which is the peak of the monsoon rainy season and intercompare the individual GCMs and RCMs, the ensemble of RCMs using the same boundary forcing (hereafter referred to as "ensemble"), and the ensemble of all the RCMs (hereafter referred to as "multi-model ensemble"). For this, in addition to the spatial patterns of bias, we compute some quantitative measure for rainfall over the Sahel, the Guinea regions, and the whole West Africa (see Figure 1(b) for the delimitation of these subdomains) which are the mean bias (or bias), the root mean square difference (RMSD) and the pattern correlation coefficient (PCC). They provide information at the regional (or subregional) level and at the grid point level. Therefore, they can be considered as measures of model systematic errors and performance. 
TABLE 1: List of regional climate models (RCMs) along with the driving global climate models (GCMs).

\begin{tabular}{|c|c|c|c|c|}
\hline RCMs & ICTP-RegCM3 & MPI-REMO & SMHI-RCA & METO_HC-HadRM3P \\
\hline Institute & $\begin{array}{c}\text { Abdus Salam International } \\
\text { Centre for Theoretical } \\
\text { Physics, Italy }\end{array}$ & $\begin{array}{c}\text { Max Planck Institute, } \\
\text { Germany }\end{array}$ & $\begin{array}{c}\text { Sveriges Meteorologiska } \\
\text { och Hydrologiska institut, } \\
\text { Sweden }\end{array}$ & $\begin{array}{c}\text { Met Office-Hadley Centre, } \\
\text { UK }\end{array}$ \\
\hline Short name & RegCM3 & REMO & RCA & HadRM3P \\
\hline Resolution & $0.44^{\circ}$ & $0.44^{\circ}$ & $0.44^{\circ}$ & $0.44^{\circ}$ \\
\hline Reference & Pal et al. [39] & Jacob et al. [40] & Kjellström et al. [41] & Jones et al. [42] \\
\hline $\begin{array}{l}\text { Boundary forcing } \\
\text { (GCMs) }\end{array}$ & $\begin{array}{c}\text { ECHAM5_r3, } \\
\text { Roeckner et al. [43] }\end{array}$ & $\begin{array}{c}\text { ECHAM5_r3, } \\
\text { Roeckner et al. [43] }\end{array}$ & $\begin{array}{c}\text { HadCM3Q0, } \\
\text { Collins et al. [44] }\end{array}$ & $\begin{array}{c}\text { HadCM3Q0, } \\
\text { Collins et al. }[44]\end{array}$ \\
\hline
\end{tabular}
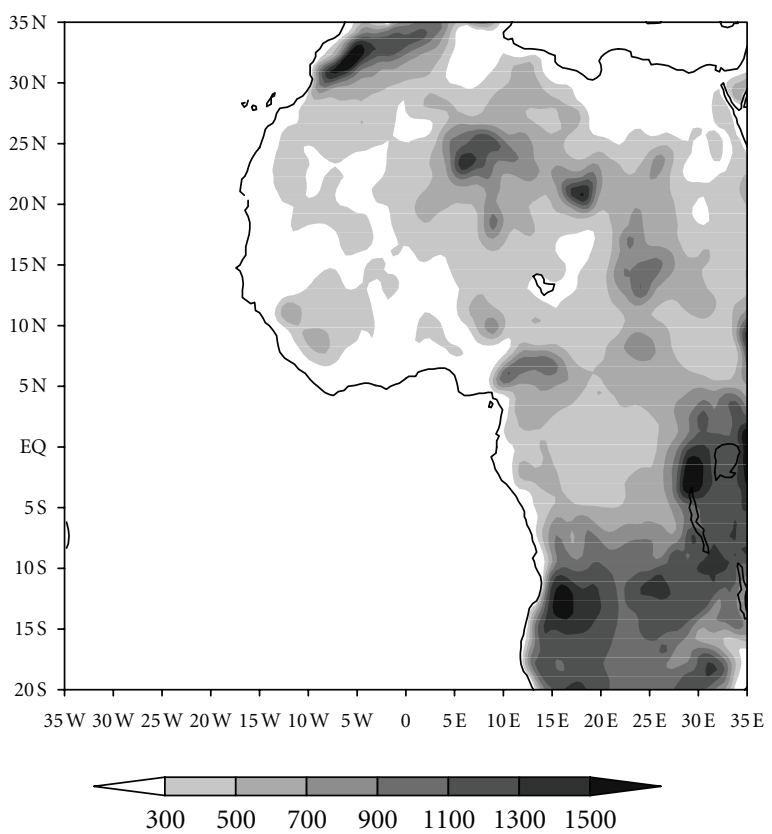

(a) West African domain and topography

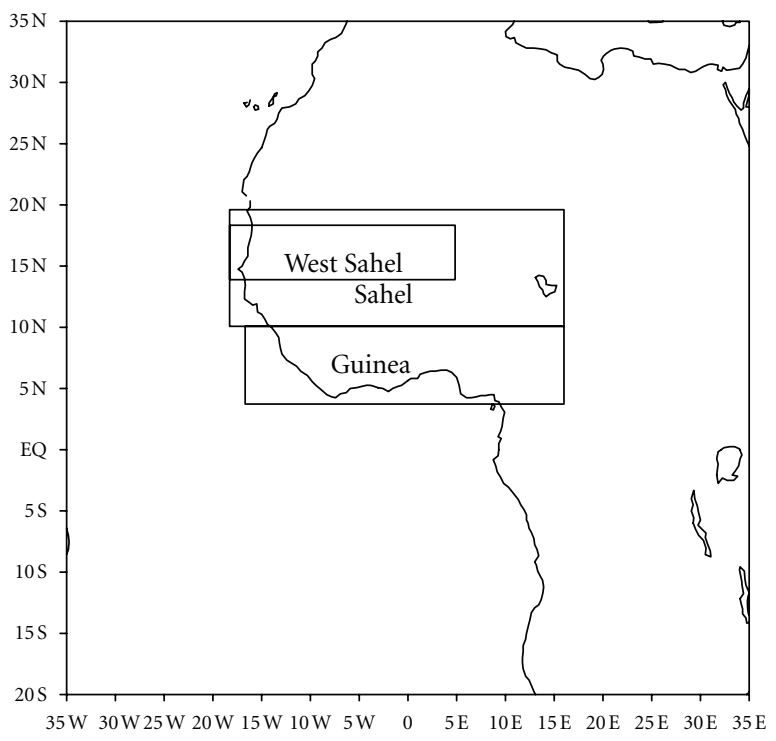

(b) Subdomains

Figure 1: AMMA domain and topography (a) Sahel, Guinea, West Africa, and Western Sahel subdomain considered for analyses through the paper (b).

\section{Results and Discussions}

3.1. Present Day Climate. The June-September (JJAS) seasonal mean temperature distribution during the present-day period (1981-2000) over West Africa is presented at Figures 2(a)-2(1) for the observation of CRU (Figure 2(a)), the ERA40, NCEP, and ERA-Interim reanalyses (Figures 2(b), 2(c), and 2(d), resp.), the two GCMs ECHAM5 and HadCM3 (Figures 2(e) and 2(i), resp.), the two RCMs RegCM3 and REMO driven by ECHAM5 (Figures 2(f) and 2(g), resp.), the two RCMs: RCA and HadRM3P (Figures 2(j) and 2(k), resp.) driven by HadCM3 and their different ensemble mean (Figures 2(h) and 2(l)). CRU observation and the reanalyses show a good agreement in locating the highest temperature values in the north (Sahara desert, Sahel) and lowest around the Gulf of Guinea, in particular over the peak of mountainous regions of Guinea Highlands, Cameroun mountains, and Jos Plateau. Note that these latter cold temperatures are missing in NCEP, confirming hence the existence of discrepancies between the reanalysis products $[56,57]$.

The models capture the basic features of the spatial temperature distribution; however, they show different patterns and magnitudes of bias. For example, RegCM3 has a cold bias over the Sahara desert and Guinea coast, RCA and HadRM3P over the Sahel band, while REMO is mostly warmer (Figures $3(\mathrm{a})-3(\mathrm{~h}))$. As a result, the ensemble mean of RCMs driven by ECHAM5 outperforms the individual RCMs and the GCM simulations, while the ensemble of RCMs driven by HadCM3 fails to do that.

The corresponding rainfall patterns as well as their biases with respect to GPCP observations are displayed in Figures 4(a)-4(l) and Figures 5(a)-5(h), respectively. We use four sets of observation to account for uncertainties in the precipitation field (Sylla et al. 2011c). In fact, the differences between the various observation products (Table 2) can reach up to $10 \%$ at the regional level, while over the whole West 


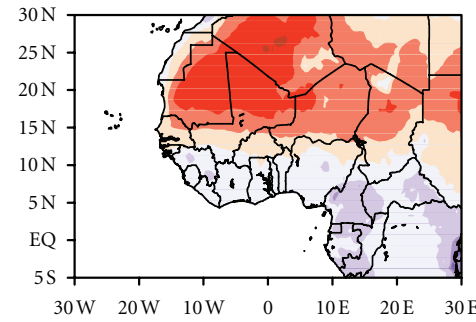

(a) JJAS CRU

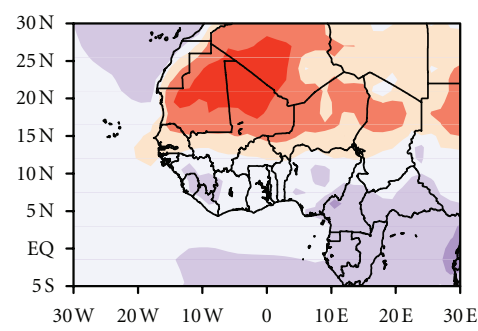

(d) JJAS ERA-Interim

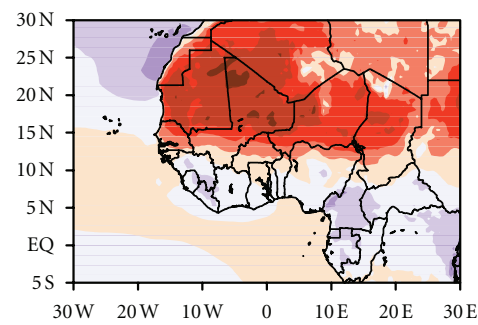

(g) JJAS REMO

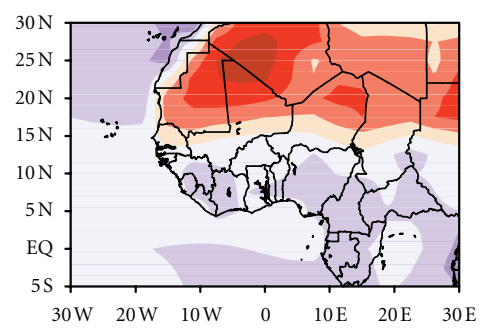

(j) JJAS RCA

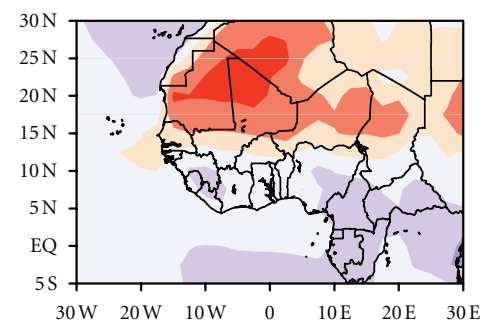

(b) JJAS ERA-40

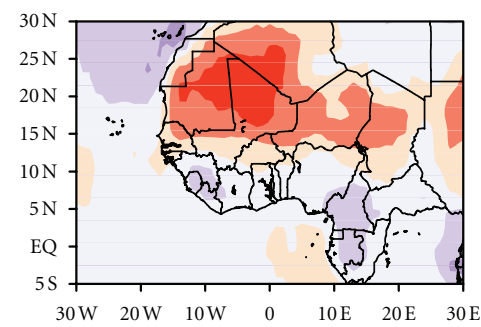

(e) JJAS ECHAM5

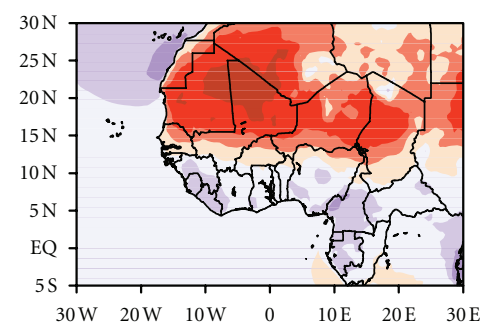

(h) JJAS Ens/ECHAM5

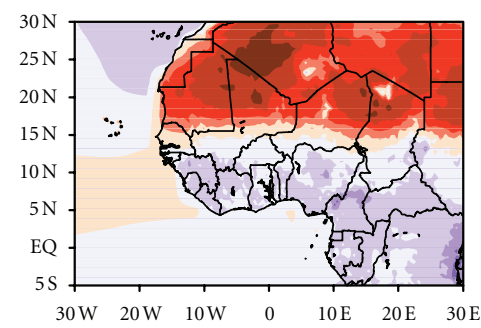

(k) JJAS HadRM3P

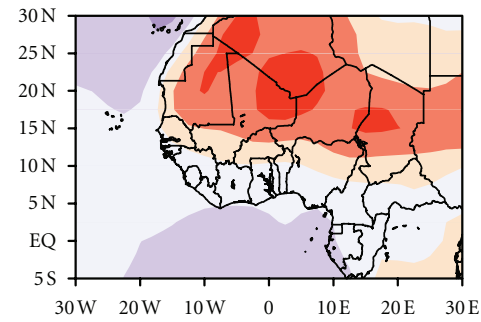

(c) JJAS NCEP

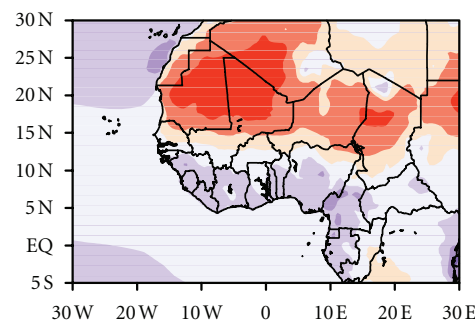

(f) JJAS RegCM3

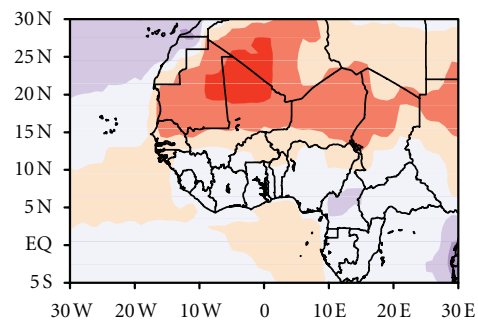

(i) JJAS HadCM3

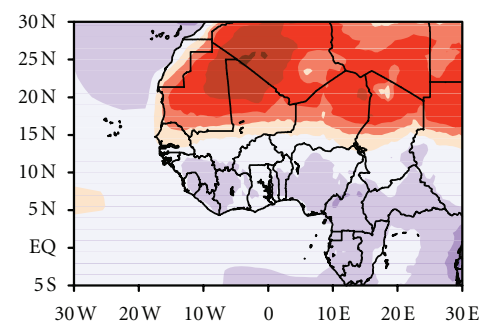

(l) JJAS Ens/HadCM3

\begin{tabular}{lll|l|l|l|l|l|l|l|l}
\hline & & & & & & & \\
\hline 15 & 18 & 21 & 24 & 27 & 30 & 33 & 36 & 39
\end{tabular}

(m)

FIgURE 2: 1981-2000 averaged JJAS of temperature (in ${ }^{\circ} \mathrm{C}$ ) from: (a) CRU observation, (b) ERA-40 reanalysis, (c) NCEP reanalysis, (d) ERAInterim reanalysis, (e) ECHAM5, (f) RegCM3, (g) REMO, (h) Ens/ECHAM5 (ensemble mean of RCMs driven by ECHAM5), (i) HadCM3, (j) RCA, (k) HadRM3P, and (l) Ens/HadCM3 (ensemble mean of RCMs driven by HadCM3).

TABLE 2: Mean bias and spatial root mean square difference (RMSD) at different subdomains considered in Figure 1(b) for CMAP, CRU, and GPCC rainfall with respect to GPCP. Observational datasets (CMAP, CRU, and GPCC) are interpolated to GPCP grid. Bias is expressed as percentage of GPCP value while RMSD as $\mathrm{mm} /$ day.

\begin{tabular}{|c|c|c|c|c|c|c|}
\hline \multirow{2}{*}{$\begin{array}{l}\text { Observations } \\
\text { Metrics }\end{array}$} & \multicolumn{2}{|c|}{ CMAP } & \multicolumn{2}{|c|}{ CRU } & \multicolumn{2}{|c|}{ GPCC } \\
\hline & Bias & RMSD & Bias & RMSD & Bias & RMSD \\
\hline Sahel & -10.35 & 0.41 & -2.79 & 0.40 & -6.34 & 0.51 \\
\hline Guinea & 1.53 & 0.74 & 8.51 & 1.31 & 3.33 & 1.17 \\
\hline West Africa & -5.18 & 0.49 & 2.86 & 0.69 & -2.30 & 0.69 \\
\hline
\end{tabular}




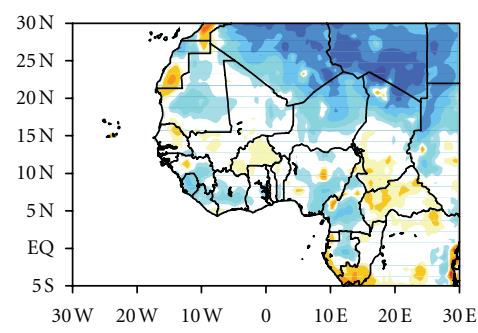

(a) ECHAM5-CRU

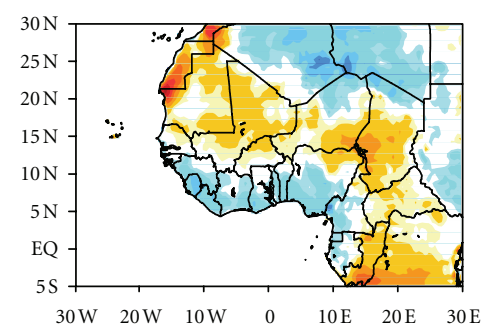

(d) Ens/ECHAM5-CRU

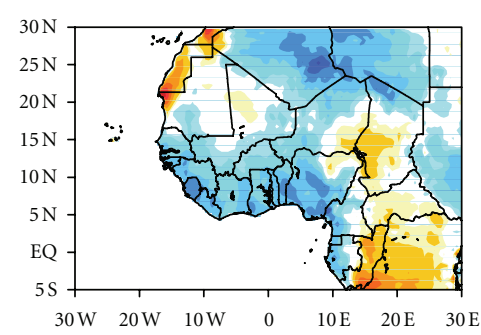

(b) RegCM3-CRU

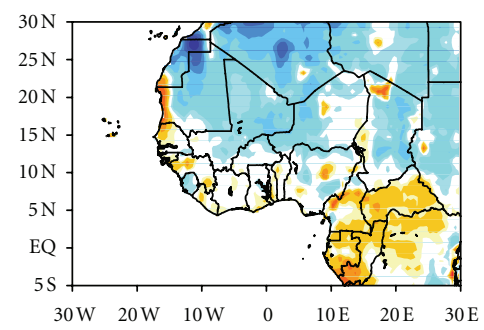

(e) HadCM3-CRU

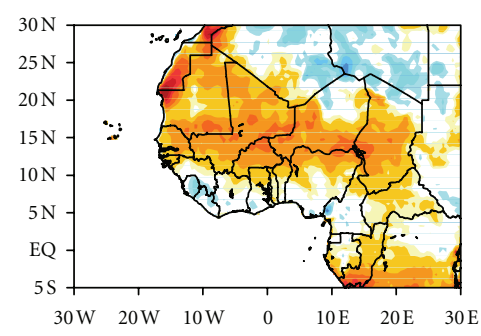

(c) REMO-CRU

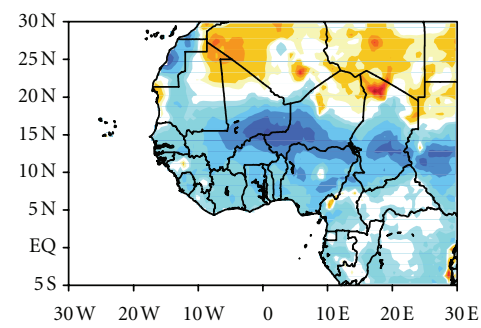

(f) RCA-CRU

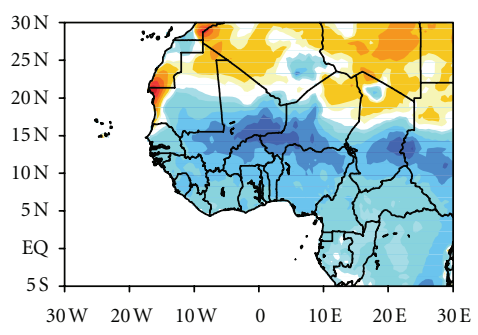

(g) HadRM3P-CRU

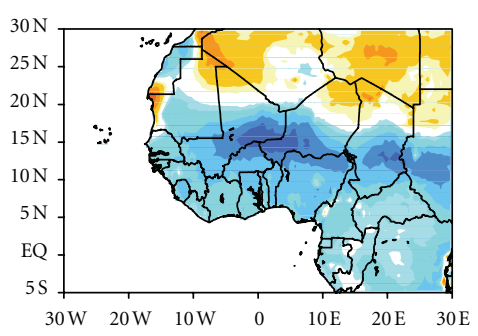

(h) Ens/HadCM3-CRU

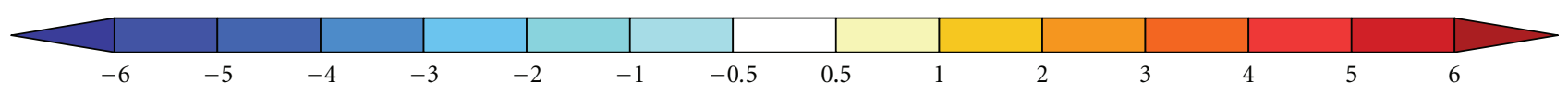

(i)

Figure 3: 1981-2000 averaged JJAS bias of temperature (in ${ }^{\circ} \mathrm{C}$ ) for (a) ECHAM5, (b) RegCM3, (c) REMO, (d) Ens/ECHAM5 (ensemble mean of RCMs driven by ECHAM5), (e) HadCM3, (f) RCA, (g) HadRM3P, and (h) Ens/HadCM3 (ensemble mean of RCMs driven by HadCM3) compared with CRU.

TABLe 3: Spatial pattern correlation coefficient (PCC) over West Africa from CMAP, CRU, and GPCC rainfall with respect to GPCP. Observational datasets (CMAP, CRU, and GPCC) are interpolated to GPCP grid.

\begin{tabular}{lccc}
\hline Observations & CMAP & CRU & GPCC \\
\hline PCC & 0.985 & 0.981 & 0.974 \\
\hline
\end{tabular}

Africa it does not exceed 5\%. Although these products exhibit some differences, their patterns show a good agreement, with PCCs of more than 0.97 (Table 3). For the spatial distribution, observations (CRU, GPCC, CMAP, and GPCP) locate the main summer rainfall in a zonal and tilted band around $8^{\circ} \mathrm{N}$, with rainfall decreasing south and north of it. Precipitation maxima are, however, located in orographic regions of the Guinea highlands, Jos plateau, and Cameroun Mountains. Key differences across the observations are that CRU shows a discontinuity in the band of maximum rainfall over West Africa and GPCP has a much lower intensity along the coastlines of Cameroun/Nigeria highlands resulting in an RMSD between the two products of more than $1.3 \mathrm{~mm} /$ day over the Gulf of Guinea.

The GCMs (ECHAM5 and HadCM3) simulate a thicker rainfall band and maxima off the coast in the eastern Atlantic and the Gulf of Guinea. Substantial differences among the RCMs are noticed. Generally, RegCM3 and REMO underestimates and overestimates rainfall intensity, respectively, and, similarly to ECHAM5, exhibit a wide rainfall band but place the maxima over orographic regions. In the HadCM3-driven RCMs experiments, RCA confines much of the rainfall between $4-9^{\circ} \mathrm{N}$ hence showing an underestimation over the regions north of it, while HadRM3P displays a much better defined rainfall band but extends the rainfall a bit north and fails to capture the large intensity in the orographic zones.

The different performance of the GCMs and RCMs are highlighted at the regional level in Tables 4 and 5 summarizing the Bias, RMSD, and PCC with respect to GPCP for the individual models over the Sahel, Guinea, and whole West Africa. Although the PCCs are overall high (more than 0.8) 


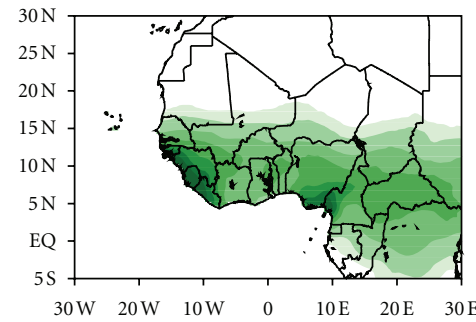

(a) JJAS CRU

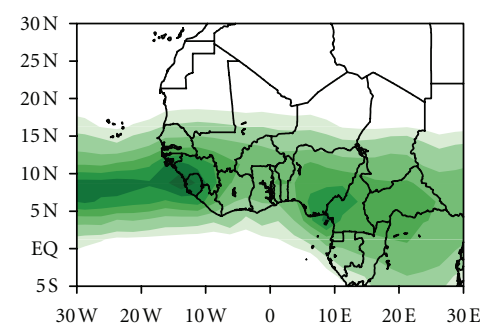

(d) JJAS GPCP

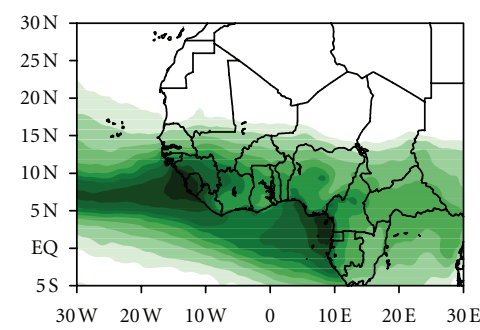

(g) JJAS REMO

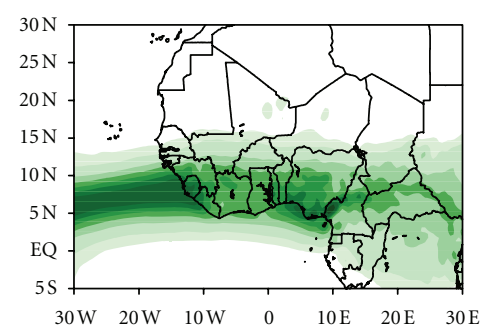

(j) JJAS RCA

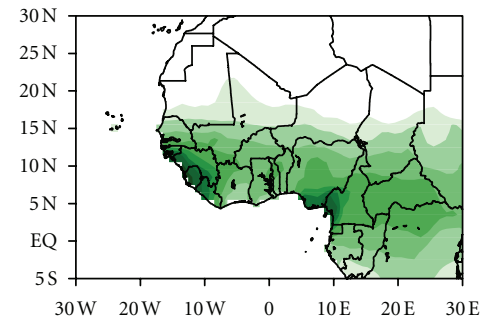

(b) JJAS GPCC

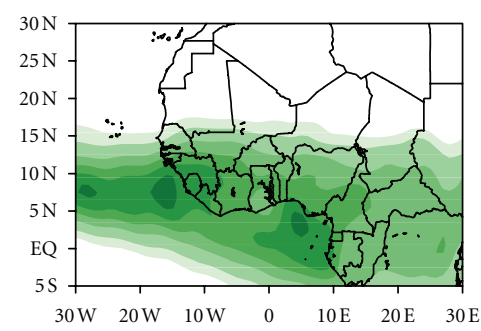

(e) JJAS ECHAM5

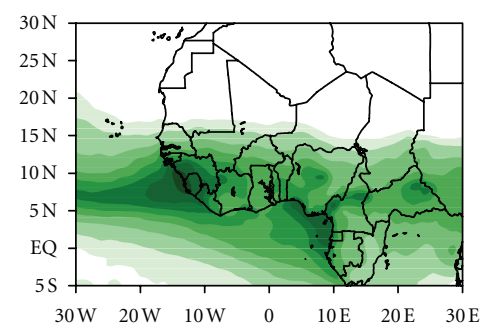

(h) JJAS Ens/ECHAM5

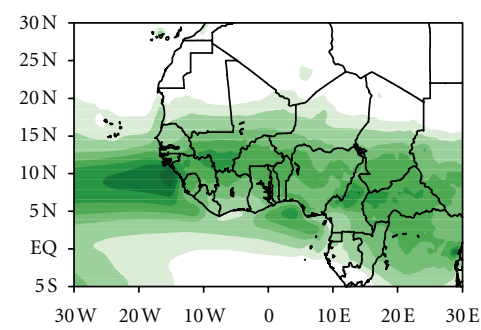

(k) JJAS HadRM3P.

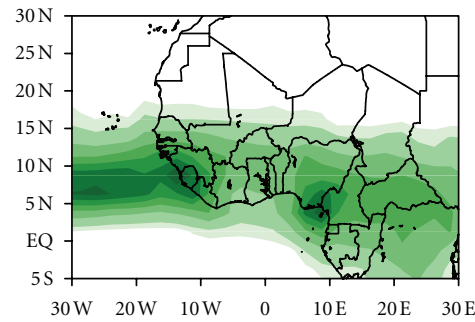

(c) JJAS CMAP

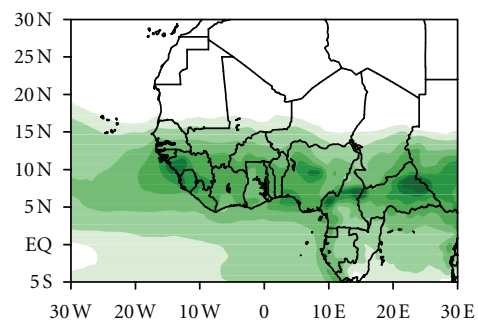

(f) JJAS RegCM3

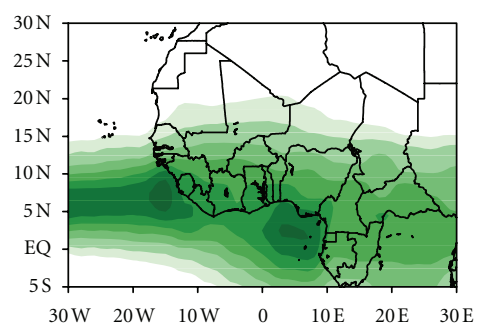

(i) JJAS HadCM3

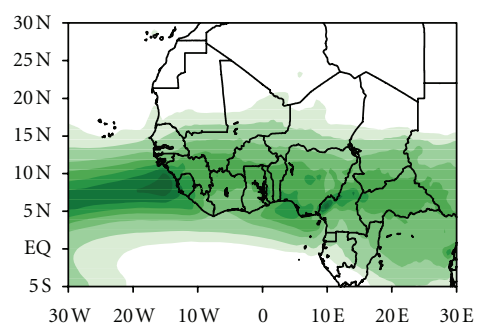

(l) JJAS Ens/HadCM3

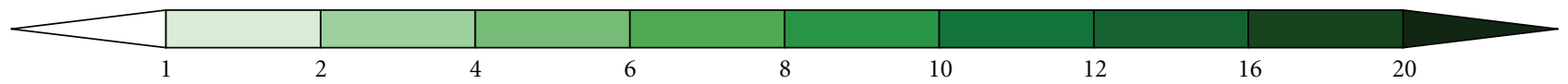

(m)

FIGURE 4: 1981-2000 averaged JJAS of precipitation (in mm/day) from: (a) CRU observation, (b) GPCC observation, (c) CMAP observation, (d) GPCP observation, (e) ECHAM5, (f) RegCM3, (g) REMO, (h) Ens/CHAM5 (ensemble mean of RCMs driven by ECHAM5), (i) HadCM3, (j) RCA, (k) HadRM3P, and (l) Ens/HadCM3 (ensemble mean of RCMs driven by HadCM3).

TABLE 4: Mean bias and spatial root mean square difference (RMSD) at different subdomains considered in Figure 1(b) from individual GCMs (ECHAM5 and HadCM3) and Individual RCMs (RegCM3, REMO, HadRM3P, and RCA) rainfall with respect to GPCP. Models output are interpolated to GPCP grid. Bias is expressed as percentage of GPCP value while RMSD as mm/day.

\begin{tabular}{lccccccccccrcr}
\hline Models & \multicolumn{2}{c}{ ECHAM5 } & \multicolumn{2}{c}{ RegCM3 } & \multicolumn{2}{c}{ REMO } & \multicolumn{2}{c}{ HadCM3 } & \multicolumn{2}{c}{ RCA } & \multicolumn{2}{c}{ HadRM3P } \\
Metrics & Bias & RMSD & Bias & RMSD & Bias & RMSD & Bias & RMSD & Bias & RMSD & Bias & RMSD \\
\hline Sahel & -18.19 & 0.79 & -14.58 & 0.76 & 8.19 & 1.37 & -7.80 & 0.91 & -31.97 & 1.52 & 6.21 & 1.23 \\
Guinea & 2.11 & 1.78 & -1.43 & 1.77 & 62.58 & 5.61 & 20.07 & 2.55 & 19.34 & 2.21 & -14.17 & 1.92 \\
West Africa & -10.39 & 1.07 & 2.46 & 1.44 & 24.94 & 2.79 & 5.68 & 1.34 & -5.18 & 1.40 & 11.92 & 1.37 \\
\hline
\end{tabular}




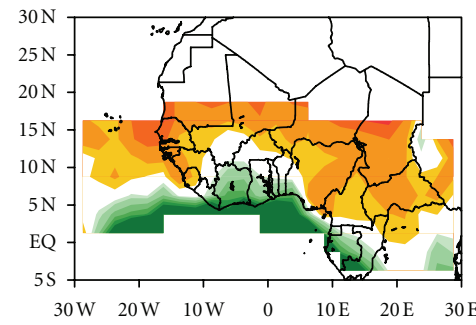

(a) ECHAM5-GPCP (\%)

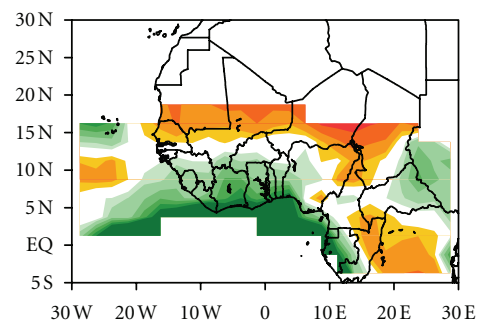

(d) Ens/ECHAM5-GPCP (\%)

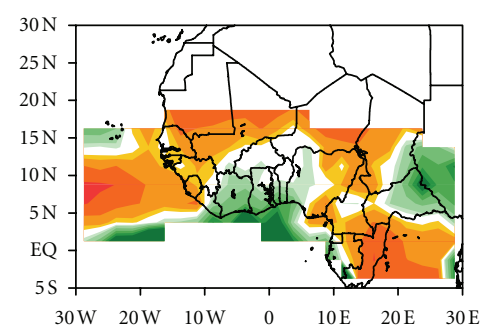

(b) RegCM3-GPCP (\%)

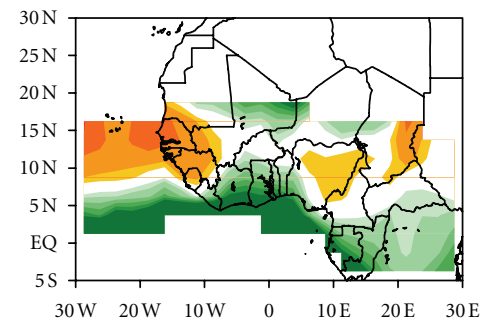

(e) HadCM3-GPCP (\%)

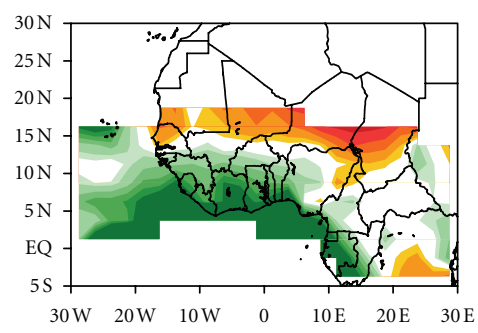

(c) REMO-GPCP (\%)

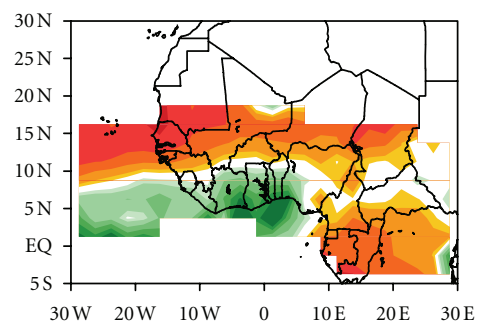

(f) RCA-GPCP (\%)

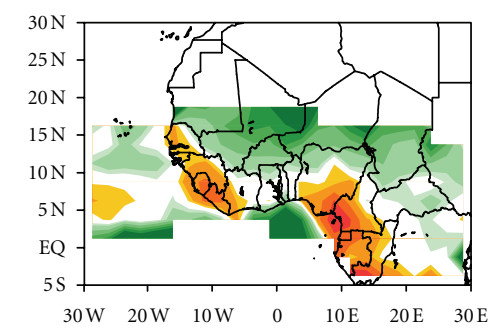

(g) HadRM3P-GPCP (\%)

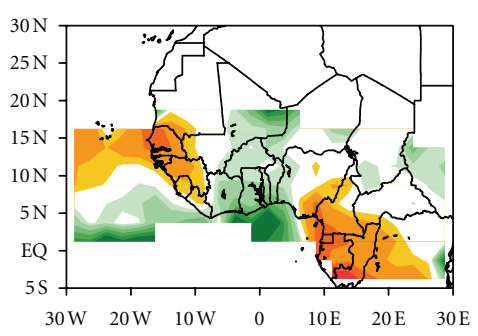

(h) Ens/HadCM3-GPCP (\%)

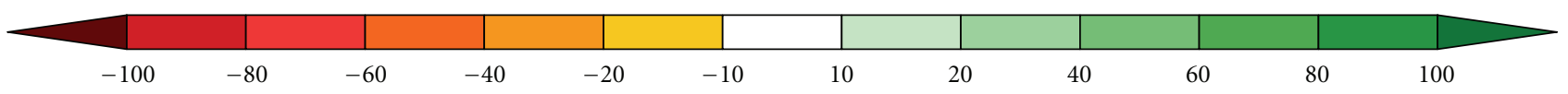

(i)

FIgURE 5: 1981-2000 averaged JJAS precipitation bias (in \%) for (a) ECHAM5, (b) RegCM3, (c) REMO, (d) Ens/CHAM5 (ensemble mean of RCMs driven by ECHAM5), (e) HadCM3, (f) RCA, (g) HadRM3P, and (h) Ens/HadCM3 (ensemble mean of RCMs driven by HadCM3) with respect to GPCP.

TABLE 5: Spatial pattern correlation coefficient (PCC) over West Africa from individual GCM (ECHAM5 and HadCM3) and individual RCM (RegCM3, REMO, HadRM3P, and RCA) rainfall with respect to GPCP. Models output are interpolated to GPCP grid.

Models ECHAM5 RegCM3 REMO HadCM3 RCA HadRM3P

\begin{tabular}{lllllll}
\hline PCC & 0.925 & 0.849 & 0.893 & 0.889 & 0.888 & 0.840
\end{tabular}

indicating a good agreement between the models and the observation, Table 4 reveals mixed results. On one hand, some RCM systematic errors are generally higher (in term of absolute value) than that of the GCMs. For example, the bias in REMO and RCA over the Guinea regions and the Sahel reaches respectively $62.58 \%$ and $-31.97 \%$ of observed values against $2.11 \%$ and $-7.80 \%$ for ECHAM5 and HadCM3. This is mostly due to the tendency of these RCMs to produce excessive rainfall over the orographic regions and to shift the rainfall band southward. On the other hand, RegCM3 and HadRM3P generate lower bias over the Sahel and the Gulf of
Guinea, respectively with respect to their driving fields. The RMSD for the individual RCMs and their ensembles employing the same driving field are found to be generally larger in the regional models with the highest values occurring in the Guinea regions. This is related to the presence of some finescale features tied to orography better represented in the RCMs than in the GCMs.

Although the RCMs offer some improvements compared to the driving GCMs, the best performances are captured in their ensemble means. In fact, they outperform the individual RCMs and the driving GCM skills in both their spatial patterns and systematic errors (see Tables 6 and 7) but also reveal different weaknesses. In the ECHAM5-driven RCM ensemble, the spatial distribution of rainfall intensity is in excellent agreement with observations (PCC of more than 0.9 ), although the rainband is still thicker than observed. Conversely, in the RCM ensemble mean employing HadCM3 as driver, the sharper rainfall band is well captured, but the orographic maxima are not simulated well. This highlights 


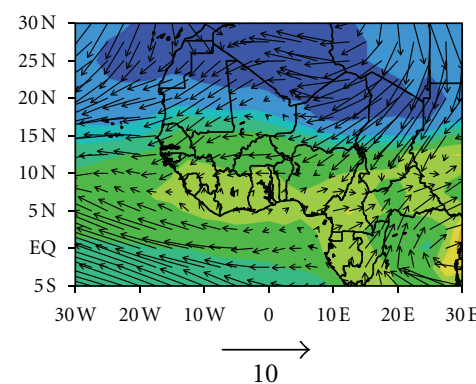

(a) JJAS NCEP

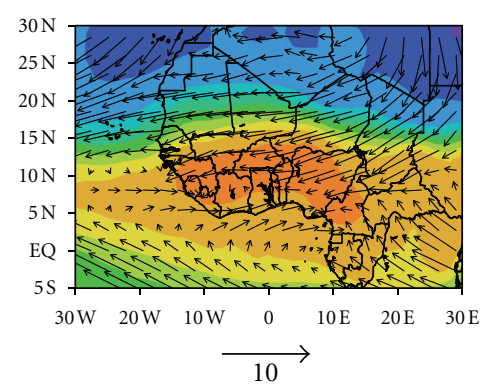

(d) JJAS ECHAM5

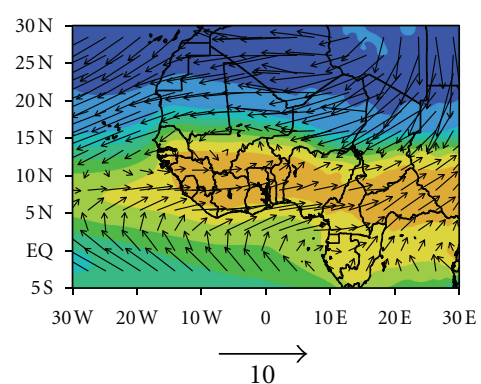

(g) JJAS Ens/ECHAM5

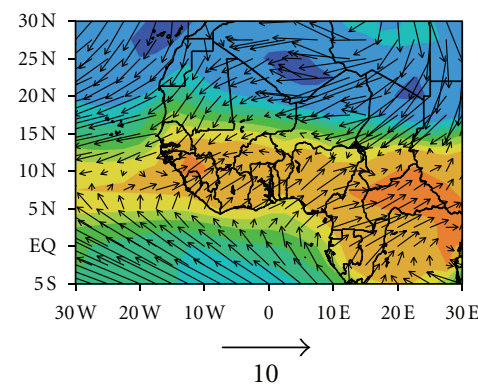

(b) JJAS ERA-40

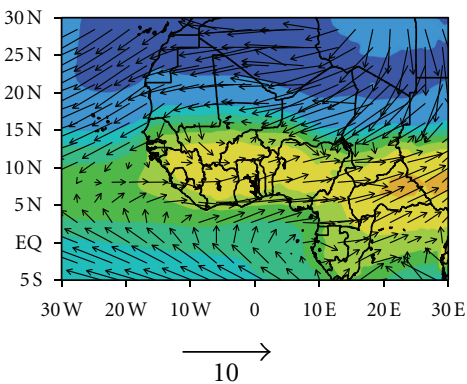

(e) JJAS RegCM3

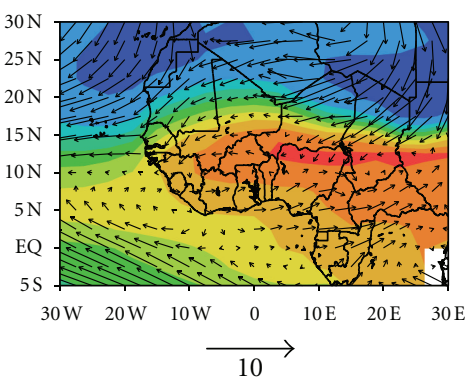

(h) JJAS HadCM3

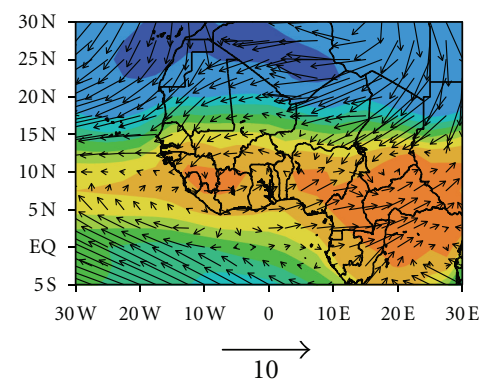

(c) JJAS ERA-Interim

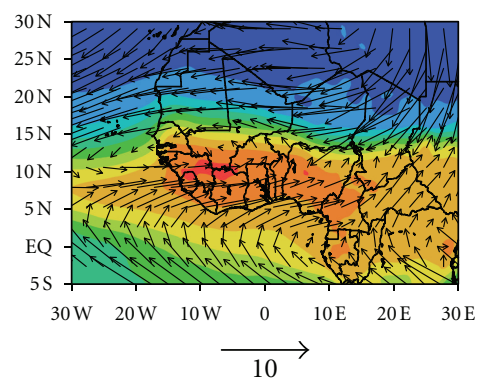

(f) JJAS REMO

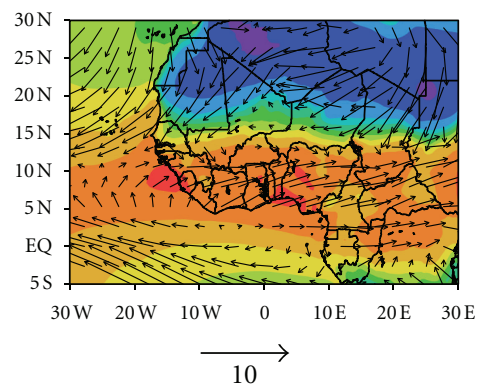

(i) JJAS RCA

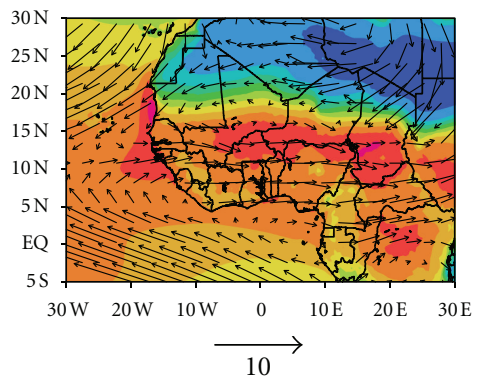

(j) JJAS HadRM3P

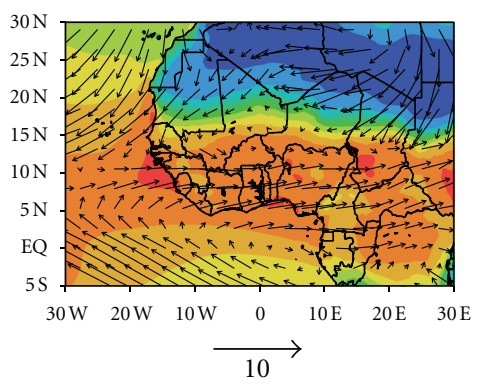

(k) JJAS Ens/HadCM3

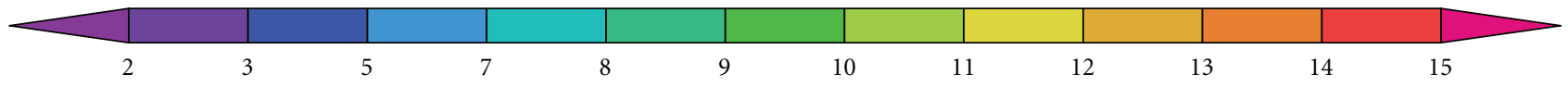

(1)

FIGURE 6: 1981-2000 averaged JJAS of $850 \mathrm{hPa}$ wind vectors (in meters per second) superimposed to specific humidity (shaded in grams per kilogram) from: (a) NCEP reanalysis, (b) ERA-40 reanalysis, (c) ERA-Interim reanalysis, (d) ECHAM5, (e) RegCM3, (f) REMO, (g) Ens/ECHAM5 (ensemble mean of RCMs driven by ECHAM5), (h) HadCM3, (i) RCA, (j) HadRM3P, and (k) Ens/HadCM3 (ensemble mean of RCMs driven by HadCM3). 


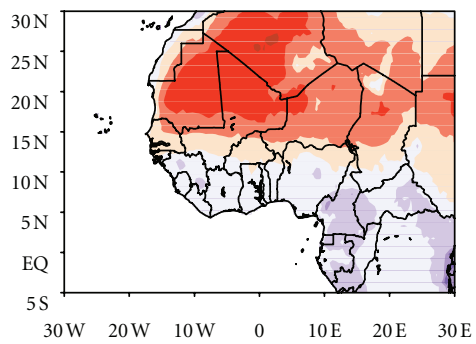

(a) JJAS CRU

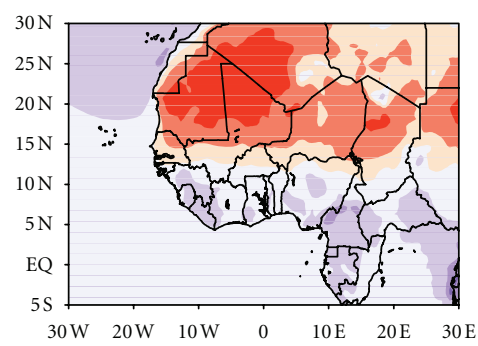

(b) JJAS ensemble GCM

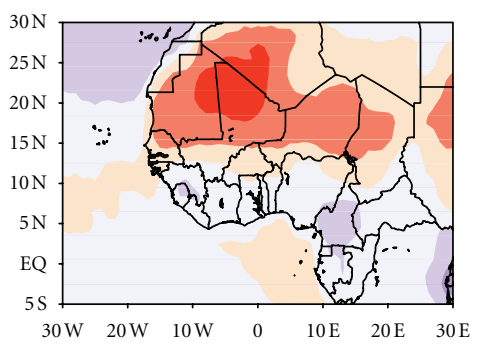

(c) JJAS ensemble RCM

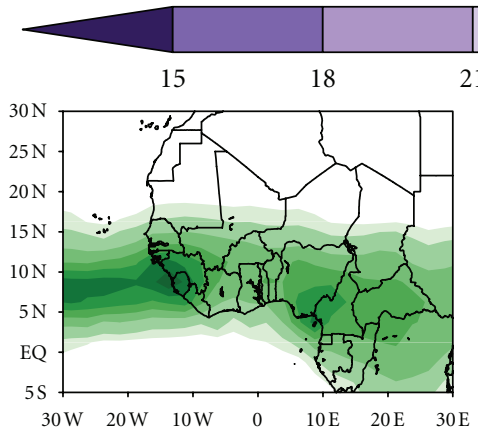

(d) JJAS GPCP

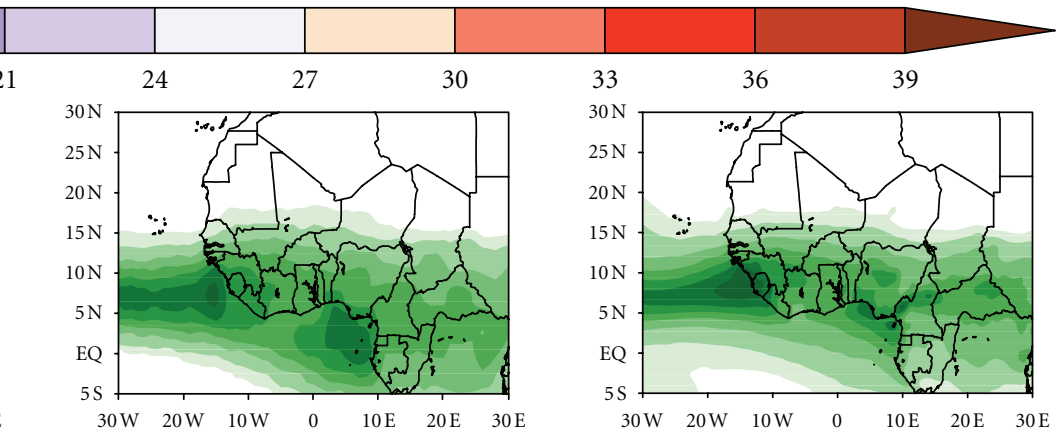

(e) JJAS ensemble GCM

(f) JJAS ensemble RCM

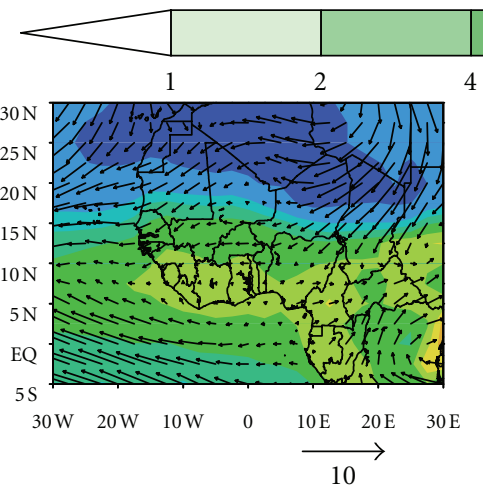

(g) JJAS NCEP reanalysis

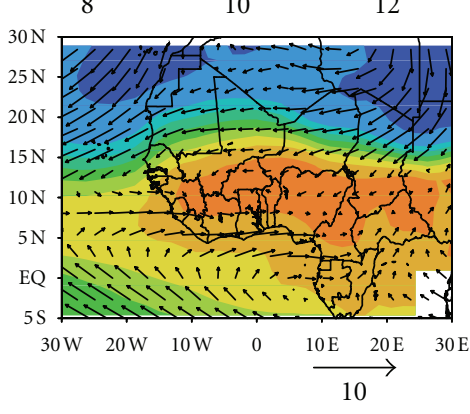

(h) JJAS ensemble GCM

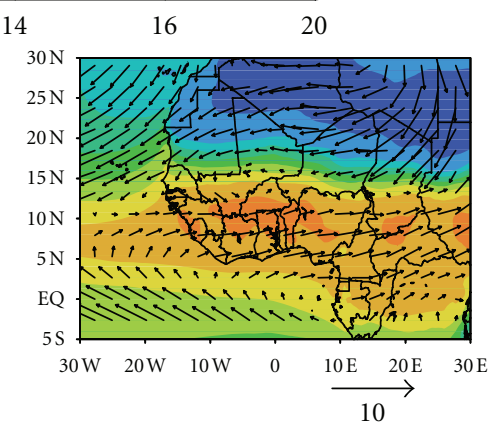

(i) JJAS ensemble RCM

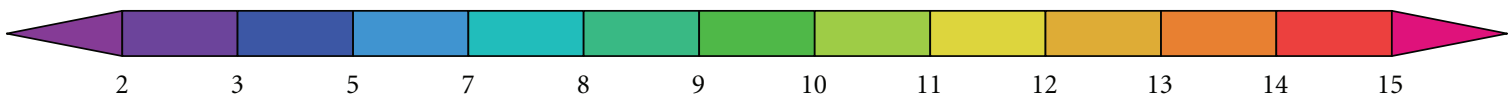

FIGURE 7: 1981-2000 averaged JJAS of temperature (top panel, in ${ }^{\circ} \mathrm{C}$ ), precipitation (middle panel, mm/day), and specific humidity (shaded; in $\mathrm{g} / \mathrm{kg}$; bottom panel) with superimposed wind vector (in $\mathrm{m} / \mathrm{s}$ ) from: (a) CRU observation, (b) mean ensemble of GCMs, (c) multi-model ensemble of the four RCMs, (d) GPCP observation, (e) mean ensemble of GCMs, (f) multi-model ensemble of the four RCMs, (g) NCEP reanalysis, (h) mean ensemble of GCMs, and (i) multi-model ensemble of the four RCMs.

the importance of the individual model skills in the performance of the ensemble mean.

A few considerations are important concerning the performance measures in Tables 4 and 5. These were calculated after upscaling all fields to the coarse resolution of the GPCP data, so that the comparison would not be affected by the difference in resolution across the datasets. However, Table 2 shows that there are significant differences across observational datasets, sometimes of the same order of magnitude as the differences with the model results. This implies that a substantial level of uncertainty is present in the evaluation of the models associated with observation uncertainties. In 


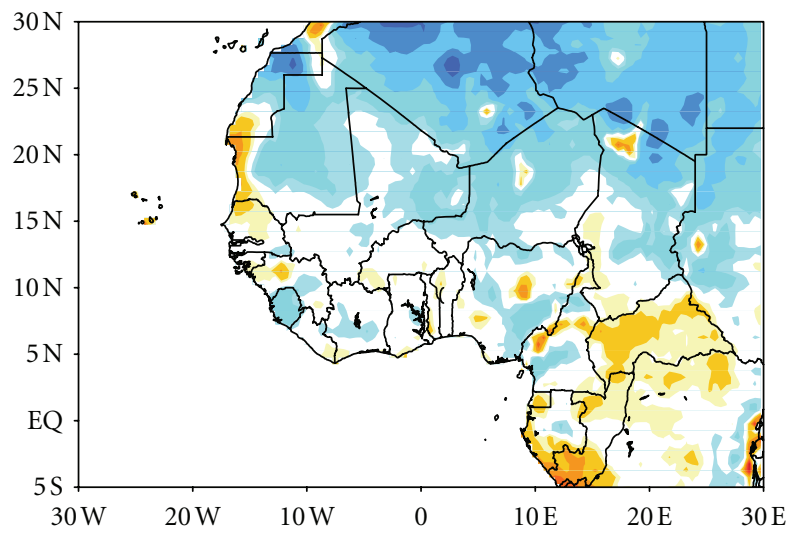

(a) Ensemble GCM-CRU

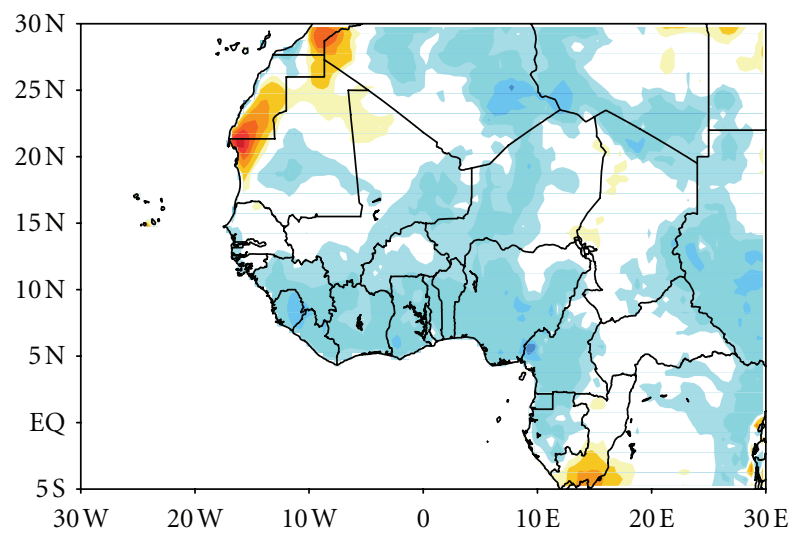

(b) Ensemble RCM-CRU

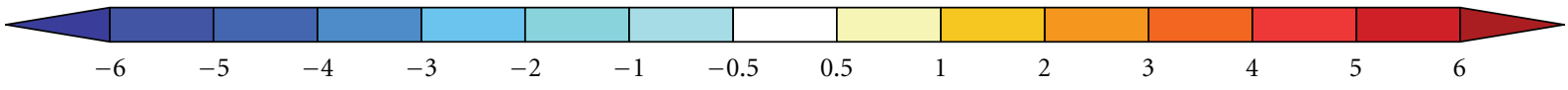

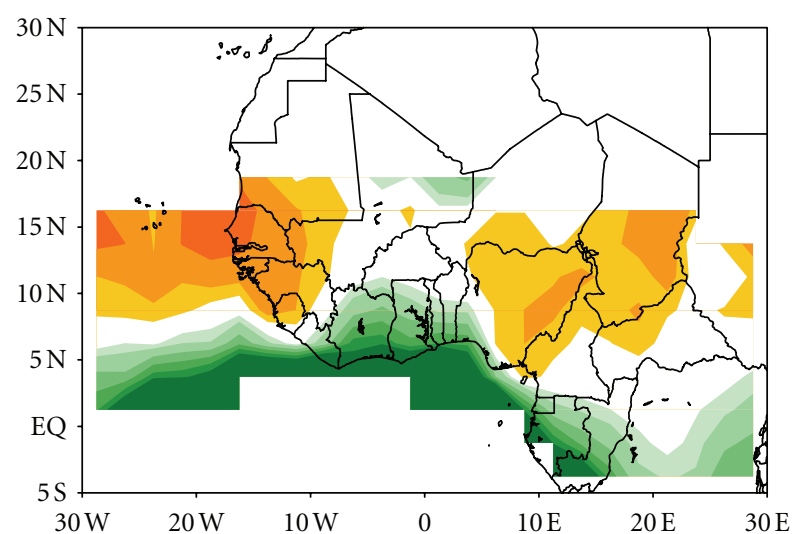

(c) Ensemble GCM-GPCP (\%)

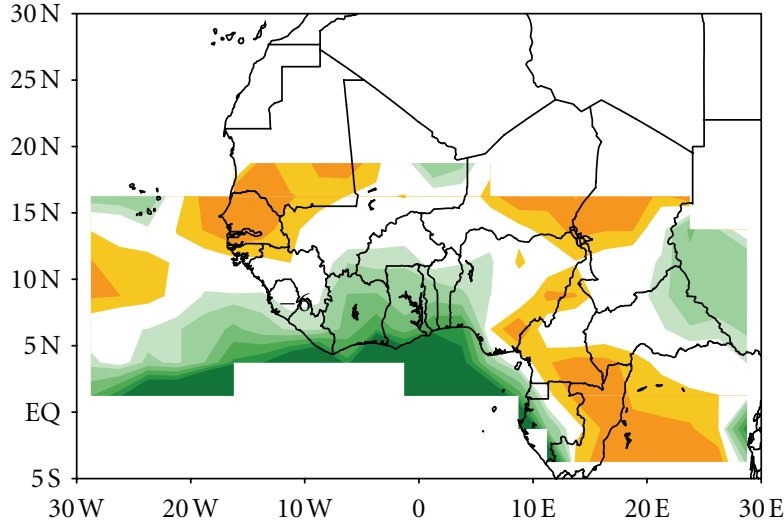

(d) Ensemble RCM-GPCP (\%)

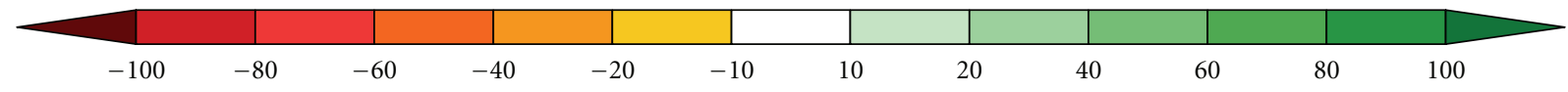

Figure 8: 1981-2000 averaged JJAS bias of temperature (top panel, in ${ }^{\circ} \mathrm{C}$ ) from: (a) mean ensemble of GCMs $\left({ }^{\circ} \mathrm{C}\right)$ and $(\mathrm{b})$ multi-model ensemble of the four RCMs compare with CRU and precipitation bias (bottom panel, in \%) from: (c) mean ensemble of GCMs and (d) multi-model ensemble of the four RCMs with respect to GPCP.

TABLE 6: Mean bias and spatial root mean square difference (RMSD) at different sub-domains considered in Figure 1(b) from the ensemble of GCMs (Ens/GCMs), the ensemble of RCMs driven by the same GCMs (Ens/ECHAM5 and Ens/HadCM3), and the ensemble of all RCMs (multi-model ensemble: Ens/RCMs) rainfall with respect to GPCP. Ensembles data are interpolated to GPCP grid. Bias is expressed as percentage of GPCP value while RMSD as mm/day.

\begin{tabular}{lccccccc}
\hline Ensembles & \multicolumn{2}{c}{ Ens/GCMs } & \multicolumn{2}{c}{ Ens/ECHAM5 } & \multicolumn{2}{c}{ Ens/HadCM3 } & \multicolumn{2}{c}{ Ens/RCMs } \\
Metrics & Bias & RMSD & Bias & RMSD & Bias & RMSD & Bias \\
\hline Sahel & -12.99 & 0.81 & -4.69 & 0.88 & -3.55 & 0.90 & -4.12 \\
Guinea & 11.09 & 2.11 & 32.87 & 3.19 & 5.14 & 1.65 & 19.00 \\
West Africa & -2.35 & 1.13 & 14.25 & 1.76 & 4.35 & 1.01 & 9.30 \\
\hline
\end{tabular}




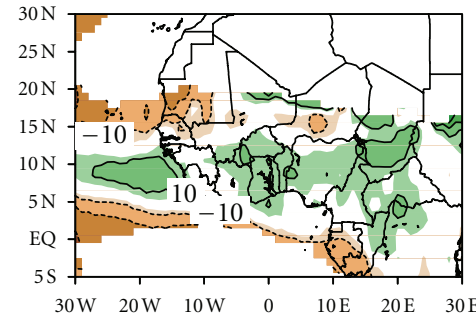

(a) JJAS ECHAM5

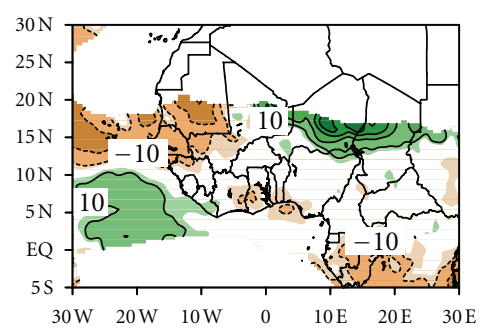

(d) JJAS Ens/ECHAM5

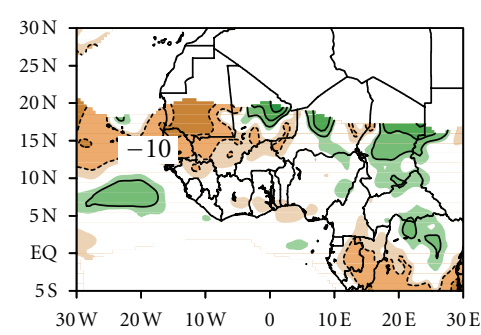

(b) JJAS RegCM3

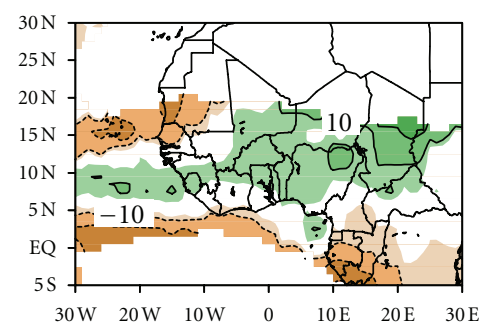

(e) JJAS HadCM3

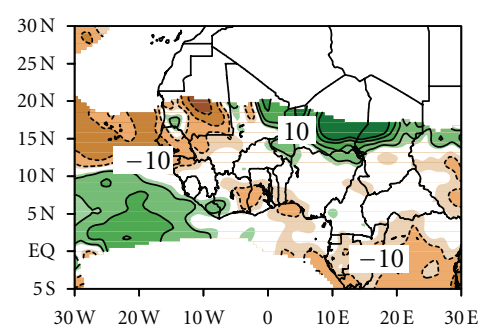

(c) JJAS REMO

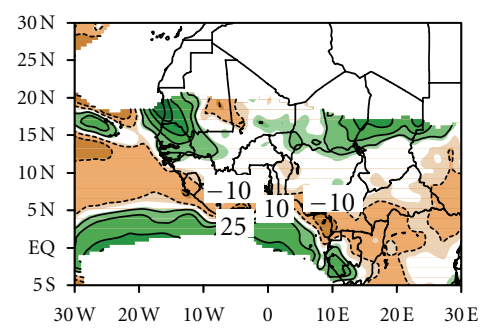

(f) JJAS RCA

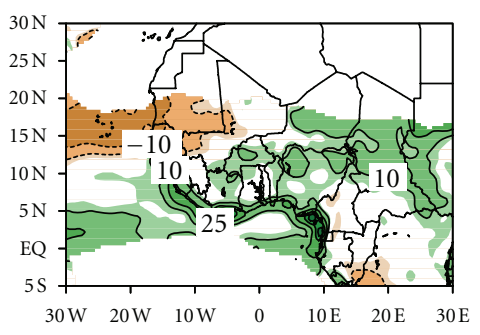

(g) JJAS HadRM3P

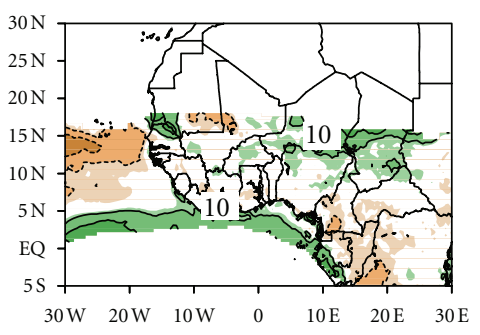

(h) JJAS Ens/HadCM3

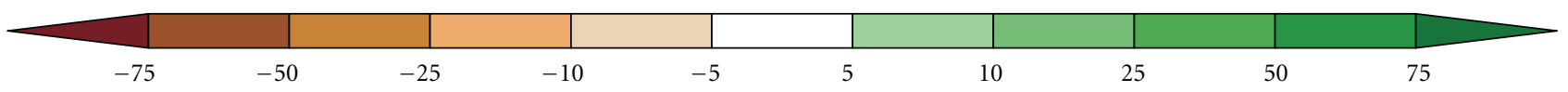

(i)

FIGURE 9: Averaged JJAS difference between the future (A1B: 2031-2050) and the reference period (1981-2000) of temperature from: (a) ECHAM5, (b) RegCM3, (c) REMO, (d) Ens/ECHAM5 (mean ensemble of RCMs driven by ECHAM5), (e) HadCM3, (f) RCA, (g) HadRM3P, and (h) Ens/HadCM3 (mean ensemble of RCMs driven by HadCM3).

TABle 7: Pattern correlation coefficient (PCC) over West Africa from the ensemble of RCMs driven by the same GCMs (Ens/ECHAM5 and Ens/HadCM3) and the ensemble of all RCMs and all GCMs (multi-model ensemble: Ens/RCMs and Ens/GCMs) rainfall with respect to GPCP. Ensembles data are interpolated to GPCP grid.

\begin{tabular}{lcccc}
\hline Ensemble Ens/GCMs & Ens/ECHAM5 & Ens/HadCM3 & Ens/RCMs \\
\hline PCC & 0.916 & 0.933 & 0.942 & 0.949 \\
\hline
\end{tabular}

particular, because of low station density the observation datasets may be characterized by especially high uncertainties in remote regions of Africa.

The seasonal (JJAS) mean of the $850 \mathrm{hPa}$ specific humidity and superimposed wind fields are shown in Figures 6(a)6(k) for the NCEP, ERA-40, and ERA-Interim reanalyses, the GCMs, the RCMs as well as their ensemble means. All the models display a stronger monsoon flow and larger specific humidity values compared to the NCEP reanalysis but quite close to ERA-40 and ERA-Interim reanalyses. In addition, the RCMs generally simulate more intense and deeper westerlies over land with respect to the driving fields. Note that only RegCM3 is able to outperform the driving GCM by simulating a much lower amount of humidity, closer to reanalysis such as ERA-40, compared to ECHAM5. The ensemble mean of ECHAM5 driven experiments improves REMO but deteriorates RegCM3 simulations, although it shows a better performance than the GCM. In contrast, the ensemble mean based of HadCM3-driven RCMs amplifies the overestimation of humidity in the Guinea region.

It is thus evident that significant performance differences exist between the driving GCMs and nested RCMs and among the RCMs driven by the same GCM. This illustrates the importance of the representation of local/regional processes [47] tied to the internal dynamics of the RCM [29]. Despite these differences, similarities in the simulated specific humidity between REMO and ECHAM5 and between HadRM3P and HadCM3 are found. This suggests that 


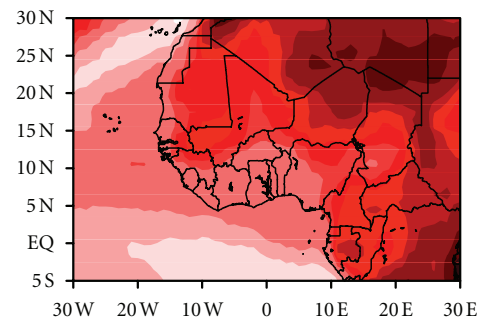

(a) JJAS ECHAM5

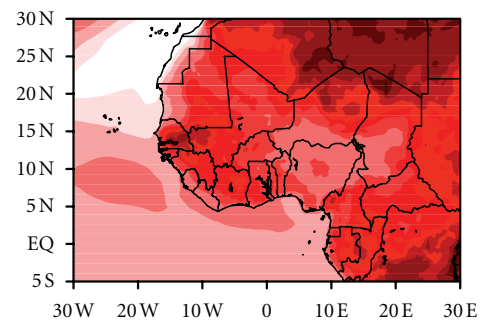

(d) JJAS Ens/ECHAM5

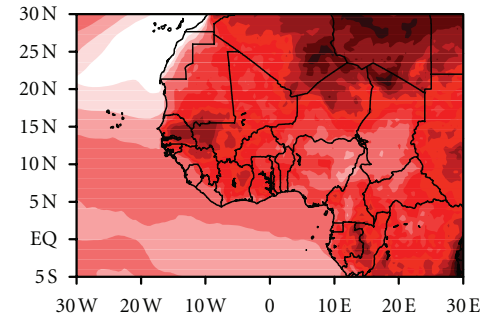

(b) JJAS RegCM3

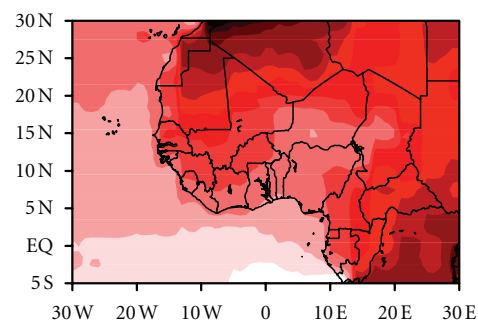

(e) JJAS HadCM3

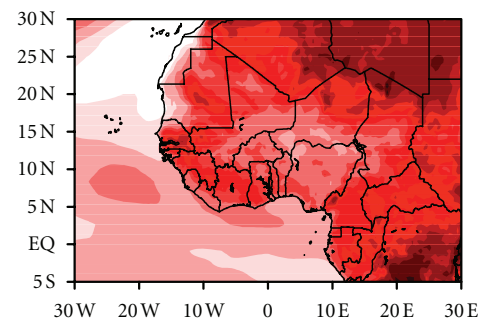

(c) JJAS REMO

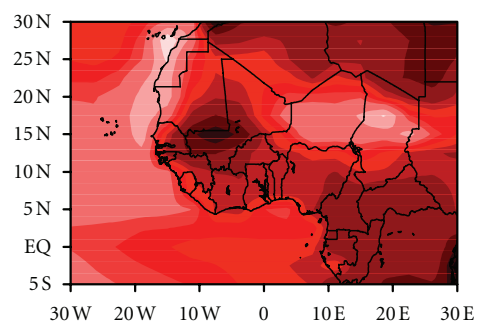

(f) JJAS RCA

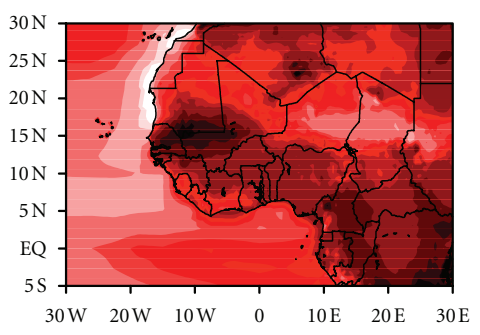

(g) JJAS HadRM3P

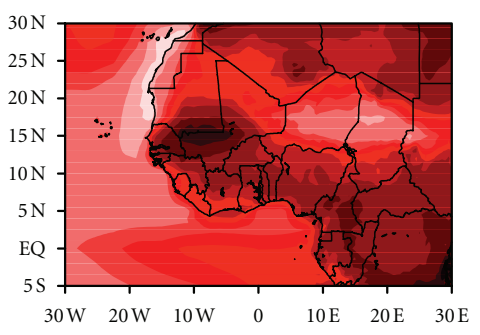

(h) JJAS Ens/HadCM3

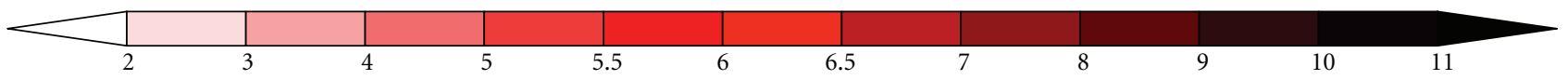

(i)

FIGURE 10: Averaged JJAS difference between the future (A1B: 2031-2050) and the reference period (1981-2000) of precipitation from: (a) ECHAM5, (b) RegCM3, (c) REMO, (d) Ens/ECHAM5 (mean ensemble of RCMs driven by ECHAM5), (e) HadCM3, (f) RCA, (g) HadRM3P, and (h) Ens/HadCM3 (mean ensemble of RCM driven by HadCM3). Precipitation change are in \% of present day values and areas where reference mean precipitation is less than $0.5 \mathrm{~mm}$ /day have been masked out. Contours represent where the changes are significant at $90 \%$ level.

although the RCM internal dynamic plays an important role in the simulation of regional climates, the large-scale environment mostly described by the forcing fields also has an influence on the model solution particularly for the temperature and moisture advection from the boundaries. In other words, the model solution is obtained through a dynamical equilibrium between the information from the lateral boundary conditions and the internal model physics/dynamics, with this equilibrium depending on features such as domain size, resolution, and size of the lateral buffer zone [14].

From this analysis, it can be seen that in the ensemble mean based on the regional climate models driven by the same GCM, some of the errors can compensate each other but still biases from the boundary forcings may remain. A further ensemble approach is to consider ensembles of different RCMs nested in different GCMs. An example of this is shown in Figures 7(a)-7(i) along with the corresponding rainfall and temperature bias in Figures $8(a)-8(d)$. Comparing these multi-model ensemble means with CRU observations shows that they both reproduce more accurately the spatial distribution of seasonal mean temperature, with the RCM multi-model ensemble capturing more details tied to the local topography. Similarly, compared to GPCP precipitation, the RCM ensemble remarkably outperforms the GCM ensemble as well as the individual RCM members, by representing a more realistic spatial distribution (PCC of around 0.95; Table 7) and, in particular, better defined rainband, orographic maxima, and rainfall values closer to observations (smaller RMSD). Similar conclusions are also found for specific humidity with the superimposed wind vectors.

We thus find that the full ensemble of RCM simulations shows the best performance when compared to the individual models or to the GCMs. This is because the different RCMs are characterized by different biases which partially counterbalance in the ensemble average. The discrepancies 


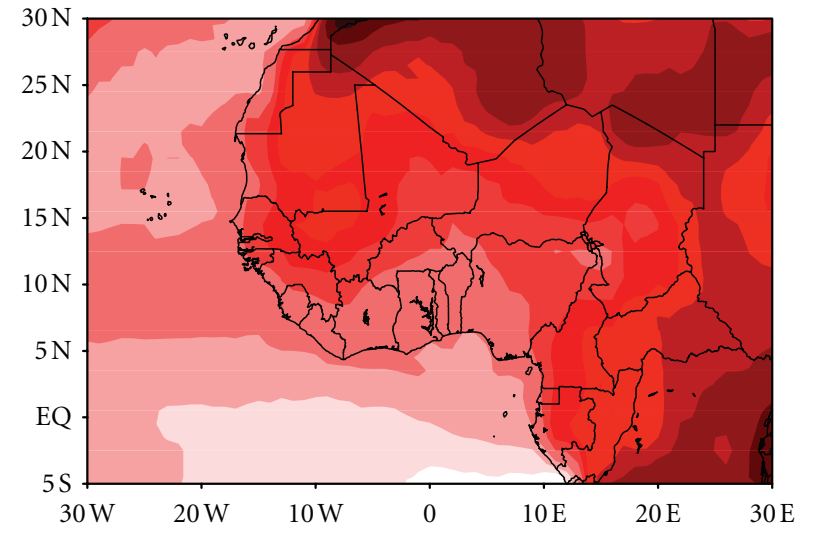

(a) JJAS ensemble GCM

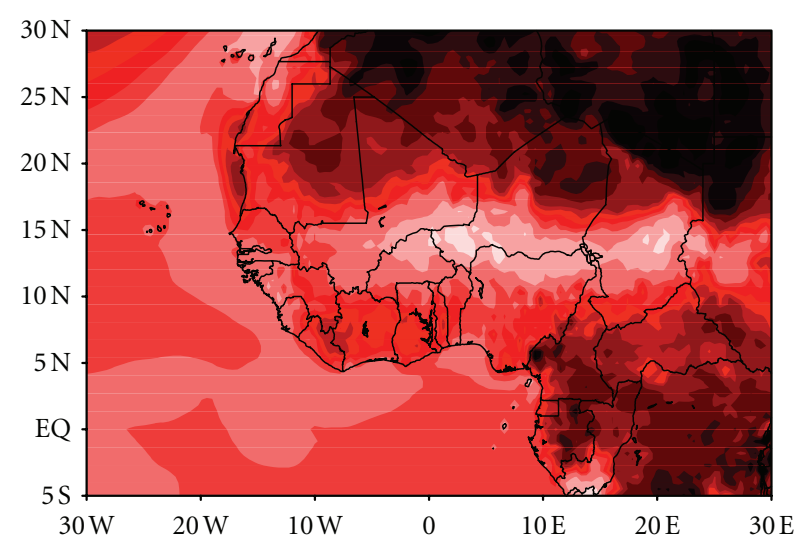

(b) JJAS ensemble RCM

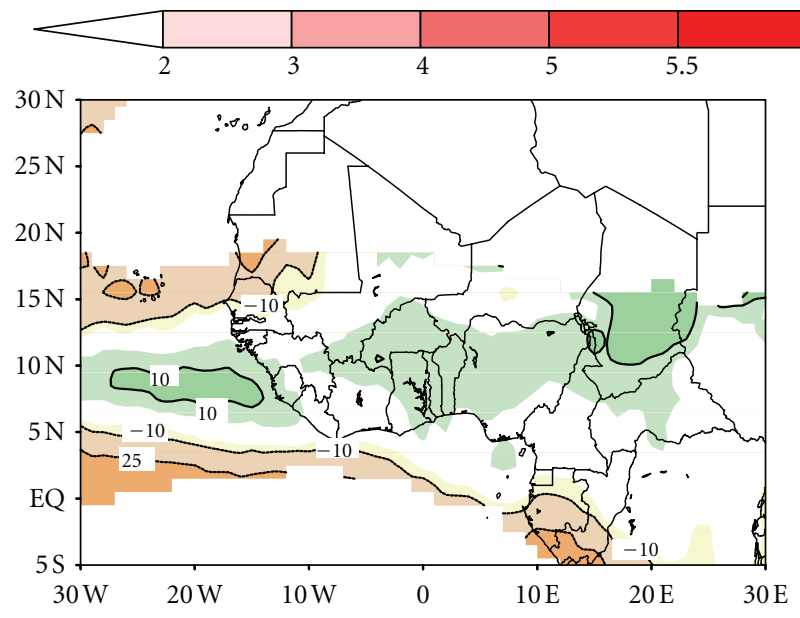

(c) JJAS ensemble GCM

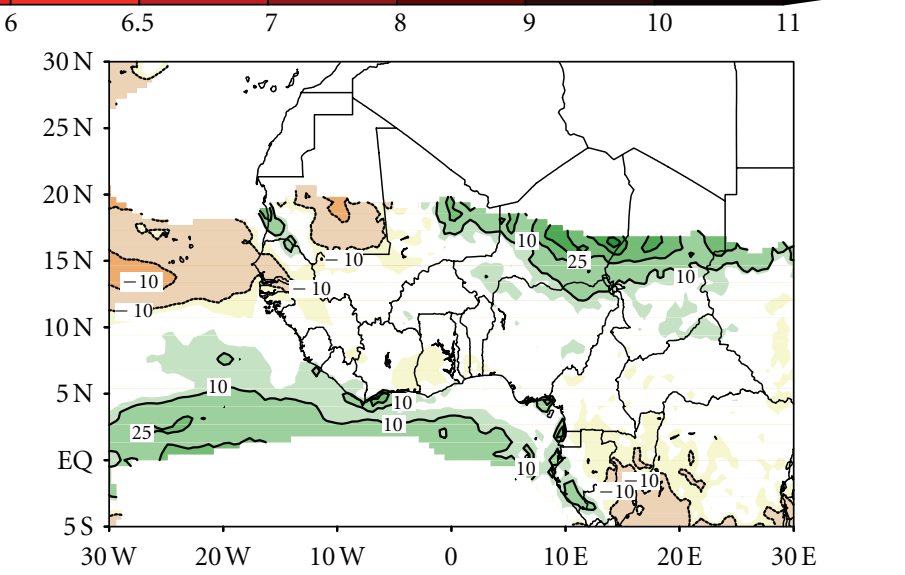

(d) JJAS ensemble RCM

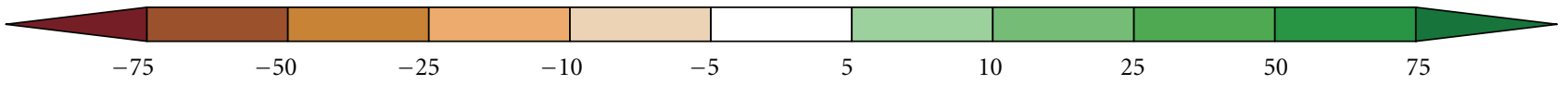

FIGURE 11: Averaged JJAS difference between the future (A1B: 2031-2050) and the reference period (1981-2000) of temperature (top panel) and precipitation (bottom panel), from: (a and c) mean ensemble average of the two GCMs; (b, d) multi-model ensemble of the four RCMs. Precipitation changes, in \% of present day values and where reference means less than $0.5 \mathrm{~mm} /$ day, are masked out. Contours represent where the changes are significant at 90\% level.

among the individual models in the simulation of the spatial patterns of rainfall and temperature, may substantially impact the simulated climate change signal $[29,58,59]$. In the next section, we will examine to which extent these differences affect the magnitude and the spatial pattern of the change signal projected by the multi-model ensemble.

\subsection{Future Climate}

3.2.1. Mean Changes. Figures $9(\mathrm{a})-9(\mathrm{~h})$ shows the temperature changes (A1B minus reference) from the driving GCMs, the nested RCMs, and their ensemble means. In good agreement with the GCMs, the RCMs exhibit overall warming over West and North Africa, with the maxima being somewhat differently located. For RegCM3 and REMO, maximum warming is located over eastern North Africa $\left(10^{\circ} \mathrm{E}-22^{\circ} \mathrm{E}\right.$; $20^{\circ} \mathrm{N}-28^{\circ} \mathrm{N}$ ) while models driven by HadCM3 exhibit a core of maximum warming over the western Sahel $\left(15^{\circ} \mathrm{W}-2^{\circ} \mathrm{W}\right.$; $10^{\circ} \mathrm{N}-18^{\circ} \mathrm{N}$ ). A common feature over the West Sahel is the existence of a core of large increase in temperature, which is missing in the driving fields and evidently originates from the local and regional processes represented by the internal dynamics of the RCMs. This is more marked in the RCA, HadRM $3 \mathrm{P}$ and their ensemble mean and is connected to the overall warmer climate shown over the Guinea and Sahel regions. The GCMs, RCMs, and their ensemble means thus 

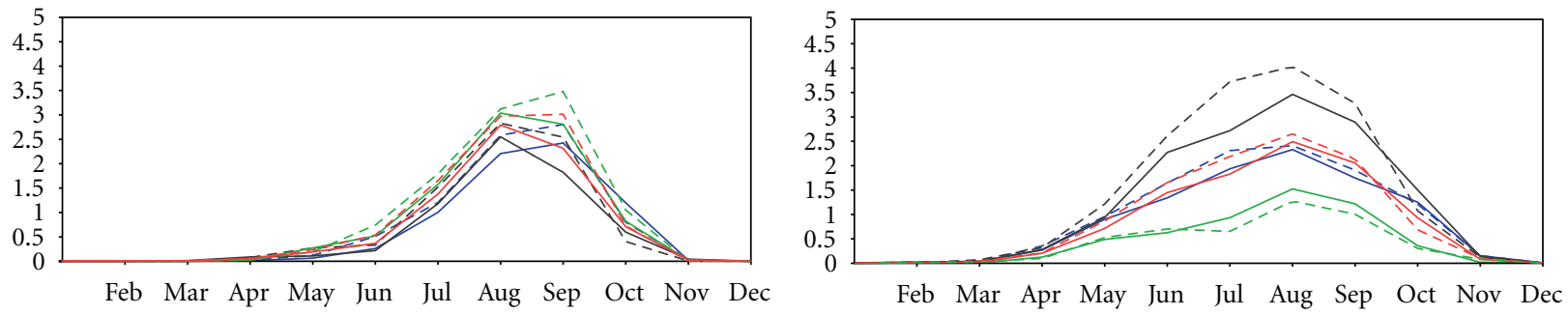

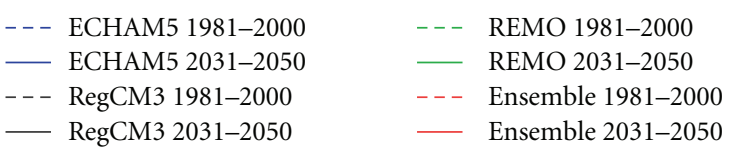

(a) With ECHAM5

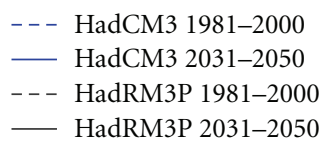

- - $\quad$ RCA 1981-2000

— RCA 2031-2050

- - Ensemble 1981-2000

— Ensemble 2031-2050

(b) With HadCM3

Figure 12: Present-day and future annual cycles of precipitation (in mm/day) over Western Sahel from, GCMs (ECHAM5 and HadCM3), RCMs (RegCM3, REMO, RCA, and HadRM3P), and the ensemble mean of RCMs driven by ECHAM5 and HadRM3P. The present day is represented by dashed lines and future by solid lines.

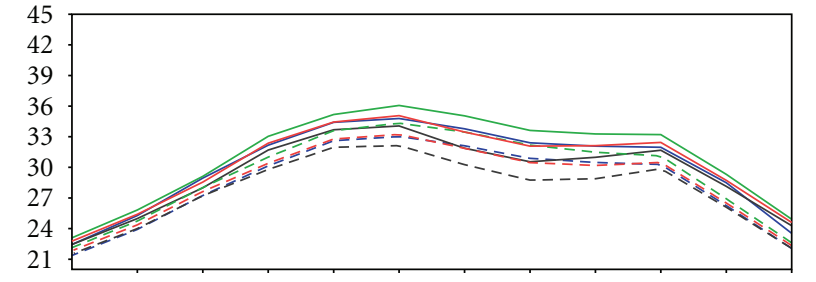

Feb Mar Apr May Jun Jul Aug Sep Oct Nov Dec

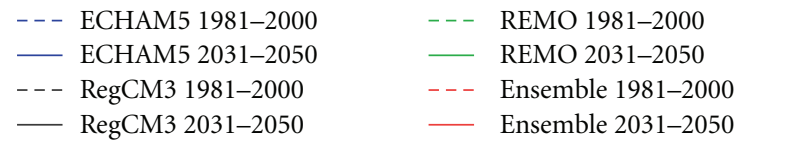

(a) With ECHAM5

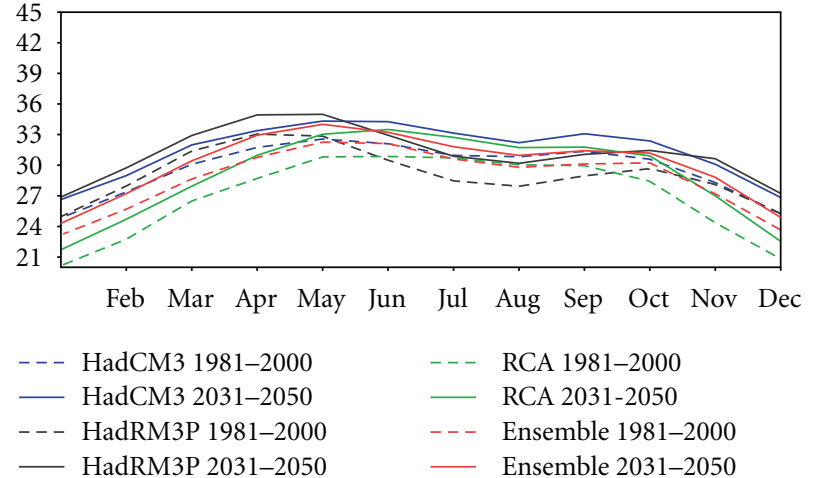

(b) With HadCM3

Figure 13: Present-day and future annual cycles of temperature (in ${ }^{\circ} \mathrm{C}$ ) over Western Sahel from: GCMs (ECHAM5 and HadCM3), RCMs (RegCM3, REMO, RCA, and HadRM3P), and the ensemble mean of RCMs driven by ECHAM5 and HadRM3P. The present-day is represented by dashed lines and future by solid lines.

simulate consistent warming but with different magnitudes and spatial patterns, which adds uncertainty to the projections.

For the projected rainfall change (Figures $10(a)-10(h)$ ), a consistent pattern of change signal off the western African coasts and over the western Sahel emerges, consisting of a pronounced decrease (more than 25\%) in precipitation for all models, except for RCA. These drier conditions are mostly associated to the larger warming (up to $10-11 \mathrm{~K}$ ) found there, probably a result of lower evaporative cooling and cloudiness. The two GCMs agree in showing this significant drying along with an increase of precipitation in regions east and south of the northern Sahel. HadRM3P strictly replicates this spatial distribution with more details, while RegCM3 and REMO show no significant changes around the regions south of the Sahel. Consequently, the ensemble of RCMs driven by ECHAM5 reveals a clear picture of climate change signal with rainfall increasing in the eastern Sahel and decreasing in the western Sahel. The ensemble of RCMs driven by HadCM3 shows a wetter climate in the East but the drying over the western part is somewhat offset by the increase of rainfall projected by RCA.

The similarities found in the driving GCMs and nested RCMs suggest that over the western Sahel the negative changes are primarily driven by the large-scale environment described by the lateral boundary forcings. Conversely, the marked differences between the global and regional model projections over other areas highlight the role of local conditions in determining the response of the regional climate to the global warming. Furthermore, the discrepancies among the RCMs in predicting future climate even when driven by the same GCM indicate that the projections are sensitive to the specific physics and internal variability of the models. These uncertainties thus suggest that a multi-model ensemble approach encompassing both RCMs and GCMs may be needed for a better evaluation of climate change over the region $[30,60]$.

The multi-model ensemble mean change accounting for all four regional climate models (regardless of the boundary forcings) is shown in Figures 11(a)-11(d). Consistent with 


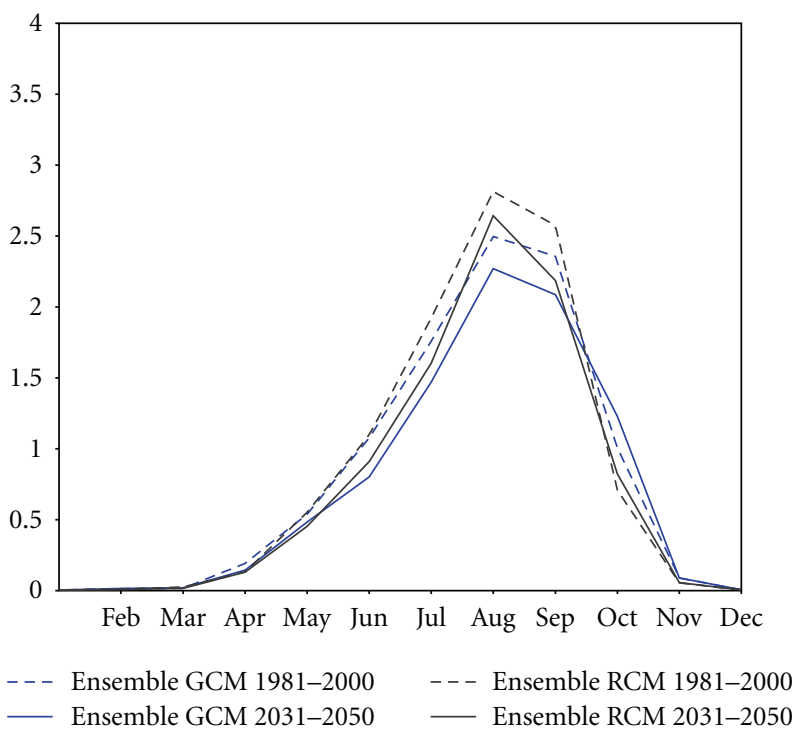

(a) Precipitation

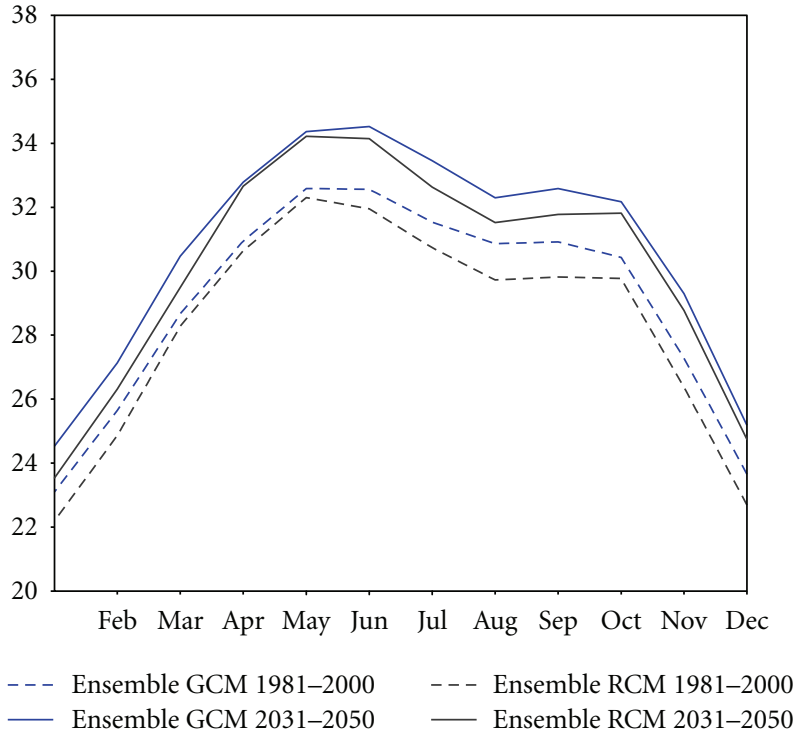

(b) Temperature

Figure 14: Present-day and future annual cycles of simulated precipitation (in mm/day; (a)) and temperature (in ${ }^{\circ} \mathrm{C}$; (b)) from: mean ensemble of the two GCMs and multi-model ensemble mean of the four RCMs over Western Sahel. The present day is represented by dashed lines and the future by solid line.

the individual member's projections, the multi-model ensemble shows a general increase of surface air temperature with maximum warming occurring over the northern and central Africa. The RCM ensemble predicts much larger warming than the GCM average over western and north-east Sahel. Concerning the rainfall changes, the multi-model ensemble confirms the emerging picture consisting of summer drying over the western Sahel in conjunction with the large warming there. Paeth et al. [30] found a drying trend using an ensemble of nine RCMs. Therefore, this appears to be a consistent result.

3.2.2. Changes in the Annual Cycle. To investigate the link between the decrease in mean rainfall and the monsoon season over the western Sahel (e.g., sub-domains in Figure 1(b)), we perform an area average of rainfall and temperature for both present-day and future climate and display the mean annual cycles of rainfall over this region in Figure 12 for the individual GCM, the nested RCMs and their ensembles. It is found that for ECHAM5, HadCM3, and all the RCMs, except RCA, the future annual cycle of rainfall curve lies below that of the corresponding present-day throughout the whole year, with decreases being larger during the peak of the season (August). This suggests that drier conditions projected by these models are mostly due to a weakening of the peak monsoon rainfall and a slight narrowing seasonal cycle over the region. The opposite is found for the RCA projection. In the case of HadCM3, the negative changes occur mostly as a consequence of less intense rainfall amount simulated during the onset and installation phase of the present-day monsoon season. Overall, these results indicate a delay in the rainfall seasonal cycle in response to increasing GHG concentration [61]. For the temperature annual cycle (Figure 13), the future climate is consistently and substantially warmer throughout the whole year, but the differences (compared to the presentday) are larger from May through October. Therefore, this warming is likely due to the reduction of cloud cover [4] and shortwave radiative forcing along with reduced evaporation. The multi-model ensembles employing, respectively, the four RCMs and the two driving GCMs show results similar to the majority of the models for both the precipitation and temperature annual cycle changes (Figures 14(a) and 14(b)).

3.2.3. Time Series. In the previous sections, an interesting and consistent change pattern was found to be a maximum drying associated to a larger warming over Western Sahel. Therefore, it is useful to examine the time series over that region from the late 20th through the middle of the 21st centuries to gain insights on possible changes in variability that might be associated with these mean changes. These time series are displayed in Figures 15(a) and 15(b). Both for temperature and precipitation, none of the models appears to show significant changes in interannual variability, however an interesting threshold effect is evident, in which the warming and drying trends ensue only after the year 2020, with little change after that. This suggests that threshold behavior and multidecadal variability, both being non-linear effects, can strongly affect the climate change signal and thus need to be carefully considered when developing climate change scenarios [34].

\section{Summary and Conclusions}

In this paper, we analyzed and intercompared the performance and the projected changes of individual global and 


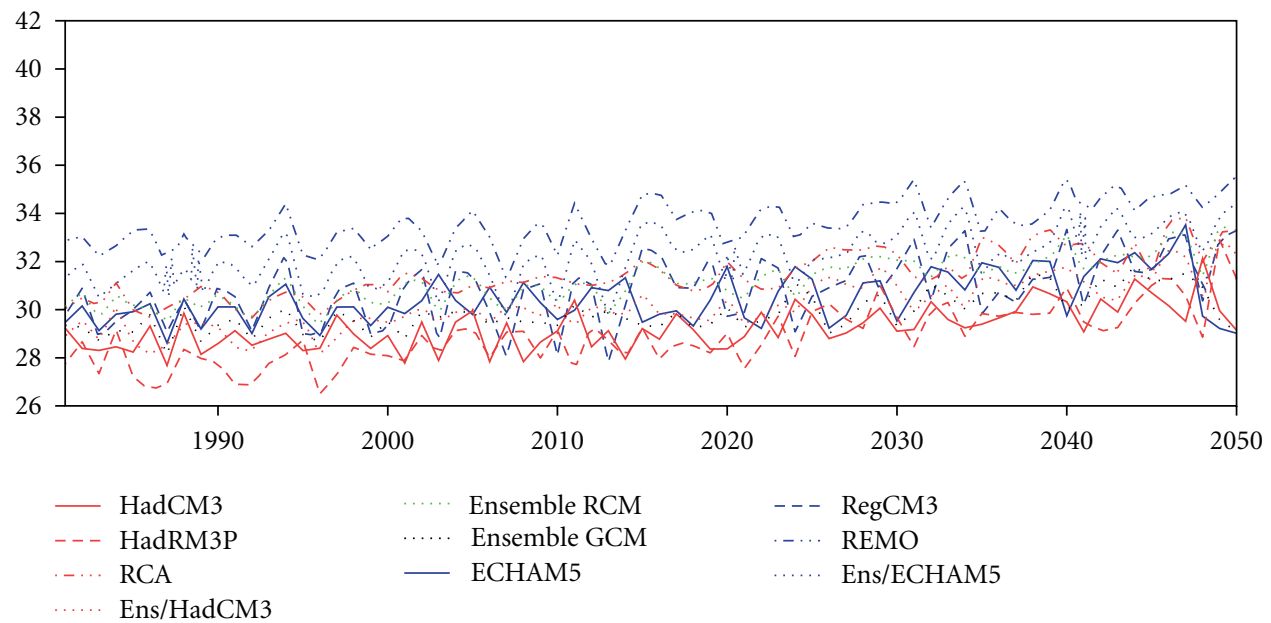

(a) Temperature

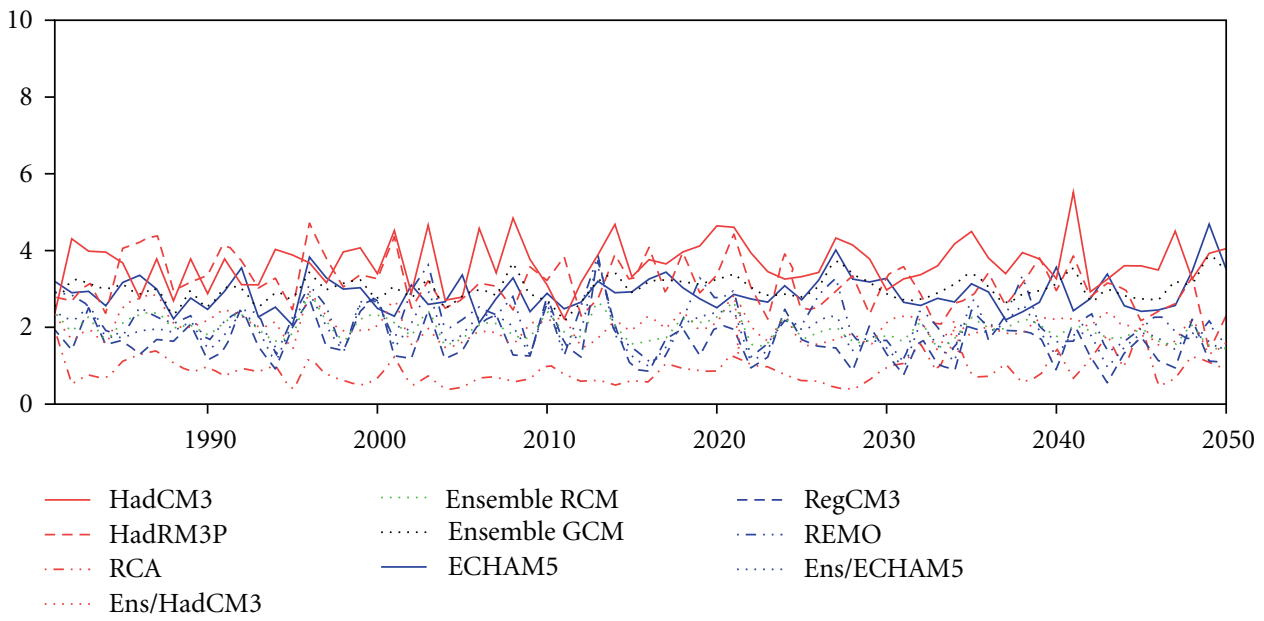

(b) Precipitation

FIGURE 15: 1981-2050 trend of (a) temperature (in ${ }^{\circ} \mathrm{C}$ ) and (b) precipitation (mm/day) by GCMs, RCMs, the ensemble means and multimodel ensemble mean of GCMs and RCMs over Western Sahel.

regional climate models, along with different sets of model ensembles, for the West Africa region. First, we found mixed results in terms of RCMs improving the simulation of climate patterns compared to the driving GCMs. In the case of precipitation, the GCMs shift the monsoon rain band southward and the individual RCMs show patterns dominated by dry biases over land. The ensembles based on RCMs employing the same GCMs as boundary forcing outperforms some of the features of the individual members and the driving global climate model. However, the best performance is attained when averaging all of the available RCMs, driven by both GCMs. This is because of the counterbalancing of errors in the different models. This would suggest that the use of multi-model ensembles using a range of RCMs driven by different GCMs might provide an optimal approach to the provision of climate change scenarios over West Africa. In addition, the fact that different RCMs driven by the same GCM may have biases that are different among each other and compared to those of the GCMs indicates that local processes and relevant parameterizations are important in determining the model response to the boundary forcing.

For the future period, GCMs produce mostly drier conditions over the western Sahel and wetter conditions in regions north of the Gulf of Guinea. The RCMs predict consistent drying in conjunction with larger warming over the western regions of the interest area but show no significant rainfall changes in the southern regions. This indicates, again, that although the boundary forcing by the GCMs does influence aspects of the RCM-predicted change, the RCM projections are also sensitive to local and regional processes and how they are treated in the models. Consistent results, but with different magnitudes, are found using different sets of ensembles.

We also analyzed the annual cycles of rainfall and temperature and found that the majority of the models simulates lower peaks of rainfall and amplified temperature maxima during the future monsoon season. The inter-annual variability does not show large changes in the future projections; however most of the simulated temperature and 
precipitation change show a threshold effect, with negligible trends before 2020 and more detectable trends ensuing only thereafter.

Some considerations for our work are important. First ensemble averaging, if sufficiently large, is expected to filter out the effect of variability and other factors that may be affecting the response of individual models (e.g., specific biases). Therefore, it should provide the best estimate of the forced change signal. On the other hand, the real climate change will be only one realization, so it will be affected by variability. In addition, it could be that one of the models of the ensemble is actually correct, and therefore the ensemble average might mask that model and indeed give a conservative estimate of change. On the other hand, to date there is really no way to unambiguously establish whether one model projection is right compared to the others. The only way to circumvent this uncertainty is to provide measures of spread (i.e., uncertainty) that also account for natural interdecadal variability. However, this is really not feasible in our case because of the small ensemble we considered. Second, the two GCMs we used tend to provide similar change patterns over West Africa; however, other GCMs may provide very different patterns [11], and this will affect the RCM simulations.

In general, our results show how different sets of GCMs and RCMs ensembles can improve the simulations of rainfall and temperature over West Africa and provide consistent climate change scenarios but with different magnitude of the signal. This is relevant for the general applicability of this approach over the region, especially within the framework of the upcoming CORDEX (Coordinated Regional Climate Downscaling Experiment) activities [60] aimed at producing more robust climate changes scenarios over the region based on large multi-model ensembles.

\section{Acknowledgments}

I. Diallo is supported by the Abdus Salam International Centre for Theoretical Physics (ICTP) through the Sandwich Training Educational Programme (STEP). Therefore, the authors gratefully acknowledge ICTP and its Earth System Physics section. Thanks also to the two anonymous reviewers and the editor whose comments significantly improve the quality of this paper.

\section{References}

[1] M. Hoerling, J. Hurrell, J. Eischeid, and A. Phillips, "Detection and attribution of twentieth-century northern and southern African rainfall change," Journal of Climate, vol. 19, no. 16, pp. 3989-4008, 2006.

[2] G. S. Jenkins, A. T. Gaye, and B. Sylla, "Late 20th century attribution of drying trends in the Sahel from the Regional Climate Model (RegCM3)," Geophysical Research Letters, vol. 32, no. 22, Article ID L22705, pp. 1-4, 2005.

[3] G. Wang and E. A. B. Eltahir, "Ecosystem dynamics and the Sahel drought," Geophysical Research Letters, vol. 27, no. 6, pp. 795-798, 2000.

[4] M. B. Sylla, A. T. Gaye, G. S. Jenkins, J. S. Pal, and F. Giorgi, "Consistency of projected drought over the Sahel with changes in the monsoon circulation and extremes in a regional climate model projections," Journal of Geophysical Research D, vol. 115, no. 16, article D16108, 2010.

[5] M. Boko, I. Niang, A. Nyong et al., "Impacts, Adaptation and Vulnerability," in Africa. Climate Change 2007, M. L. Parry, O. F. Canziani, J. P. Palutikof, and P. J. van der Linden, Eds., pp. 433-467, Cambridge University Press, Cambridge UK, 2007.

[6] M. Hulme, R. Doherty, T. Ngara, M. New, and D. Lister, "African climate change: 1900-2100," Climate Research, vol. 17, no. 2, pp. 145-168, 2001.

[7] A. F. Kamga, G. S. Jenkins, A. T. Gaye, A. Garba, A. Sarr, and A. Adedoyin, "Evaluating the National Center for Atmospheric Research climate system model over West Africa: presentday and the 21st century A1 scenario," Journal of Geophysical Research D, vol. 110, no. 3, Article ID D03106, 18 pages, 2005.

[8] H. Douville, D. Salas-Mélia, and S. Tyteca, "On the tropical origin of uncertainties in the global land precipitation response to global warming," Climate Dynamics, vol. 26, no. 4, pp. 367-385, 2006.

[9] H. Christensen, B. Hewitson, A. Busuioc et al., "Regional climate projections," in Climate Change 2007, S. Solomon, D. Qin, and M. Manning, Eds., Cambridge University Press, New York, NY, USA, 2007.

[10] M. Biasutti and A. Giannini, "Robust Sahel drying in response to late 20th century forcings," Geophysical Research Letters, vol. 33, no. 11, Article ID L11706, 2006.

[11] A. Giannini, M. Biasutti, I. M. Held, and A. H. Sobel, "A global perspective on African climate," Climatic Change, vol. 90, no. 4, pp. 359-383, 2008.

[12] H. Paeth, R. Girmes, G. Menz, and A. Hense, "Improving seasonal forecasting in the low latitudes," Monthly Weather Review, vol. 134, no. 7, pp. 1859-1879, 2006.

[13] M. Rummukainen, "State-of-the-art with regional climate models," Climate Change, vol. 1, pp. 96-82, 2010.

[14] F. Giorgi and L. O. Mearns, "Introduction to special section: regional climate modeling revisited," Journal of Geophysical Research, vol. 104, pp. 6335-6352, 1999.

[15] H. Paeth, A. Capo-Chichi, and W. Endlicher, "Climate change and food security in tropical West Africa-a dynamicstatistical modelling approach," Erdkunde, vol. 62, no. 2, pp. 101-115, 2008.

[16] N. Philippon, N. Martiny, and P. Camberlin, "Forecasting the vegetation photosynthetic activity over the Sahel: a model output Statistics approach," International Journal of Climatology, vol. 29, no. 10, pp. 1463-1477, 2009.

[17] E. A. Afiesimama, J. S. Pal, B. J. Abiodun, W. J. Gutowski, and A. Adedoyin, "Simulation of West African monsoon using the RegCM3. Part I: model validation and interannual variability," Theoretical and Applied Climatology, vol. 86, no. 1-4, pp. 2337, 2006.

[18] F. Kamga and E. Buscarlet, "Simulation du climat de l'Afrique de l'ouest a l'aide d'un modele climatique régional: validation sur la période 1961-1990," La Météorologie, vol. 52, pp. 28-37, 2006.

[19] J. S. Hsieh and K. H. Cook, "A study of the energetics of African easterly waves using regional climate model," Journal of the Atmospheric Sciences, vol. 64, no. 2, pp. 421-440, 2007.

[20] M. B. Sylla, E. Coppola, L. Mariotti et al., "Multiyear simulation of the African climate using a regional climate model (RegCM3) with the high resolution ERA-interim reanalysis," Climate Dynamics, vol. 35, no. 1, pp. 231-247, 2010.

[21] H. Paeth, K. Born, R. Podzun, and D. Jacob, "Regional dynamical downscaling over West Africa: model evaluation 
and comparison of wet dry years," Meteorologische Zeitschrift, vol. 14, no. 3, pp. 349-367, 2005.

[22] S. M. Hagos and K. H. Cook, "Dynamics of the West African monsoon jump," Journal of Climate, vol. 20, no. 21, pp. 5264 5284, 2007.

[23] M. B. Sylla, A. Dell'Aquila, P. M. Ruti, and F. Giorgi, "Simulation of the intraseasonal and the interannual variability of rainfall over West Africa with RegCM3 during the monsoon period," International Journal of Climatology, vol. 30, no. 12, pp. 1865-1883, 2010.

[24] E. K. Vizy and K. H. Cook, "Development and application of a mesoscale climate model for the tropics: influence of sea surface temperature anomalies on the West African monsoon," Journal of Geophysical Research D, vol. 107, no. 3, p. 22, Article ID 4023, 2002.

[25] R. Ramel, H. Gallé, and C. Messager, "On the northward shift of the West African monsoon," Climate Dynamics, vol. 26, no. 4, pp. 429-440, 2006.

[26] W. Moufouma-Okia and D. P. Rowell, "Impact of soil moisture initialisation and lateral boundary conditions on regional climate model simulations of the West African Monsoon," Climate Dynamics, vol. 35, no. 1, pp. 213-229, 2009.

[27] M. B. Sylla, F. Giorgi, P. M. Ruti, S. Calmanti, and A. Dell'Aquila, "The impact of deep convection on the West African summer monsoon climate: a regional climate model sensitivity study," Quarterly Journal of the Royal Meteorological Society, vol. 137, no. 659, pp. 1417-1430, 2011.

[28] G. Jung and H. Kunstmann, "High-resolution regional climate modeling for the Volta region of West Africa," Journal of Geophysical Research D, vol. 112, no. 23, Article ID D23108, 2007.

[29] L. Mariotti, E. Coppola, M. B. Sylla, F. Giorgi, and C. Piani, "Regional climate model simulation of projected 21st century climate change over an all-Africa domain: comparison analysis of nested and driving model results," Journal of Geophysical Research, vol. 116, p. 22, Article ID D15111, 2011.

[30] H. Paeth, N. M. Hall, M. A. Gaertner et al., "Progress in regional downscaling of west African precipitation," Atmospheric Science Letters, vol. 12, no. 1, pp. 75-82, 2011.

[31] H. Paeth, K. Born, R. Girmes, R. Podzun, and D. Jacob, "Regional climate change in tropical and Northern Africa due to greenhouse forcing and land use changes," Journal of Climate, vol. 22, no. 1, pp. 114-132, 2009.

[32] R. Neumann, G. Jung, P. Laux, and H. Kunstmann, "Climate trends of temperature, precipitation and river discharge in the Volta Basin of West Africa," International Journal of River Basin Management, vol. 5, no. 1, pp. 17-30, 2007.

[33] P. Oettli, B. Sultan, C. Baron, and M. Vrac, "Are regional climate models relevant for crop yield prediction in West Africa?" Environmental Research Letters, vol. 6, no. 1, 2011.

[34] F. Giorgi, "Climate change prediction," Climatic Change, vol. 73, no. 3, pp. 239-265, 2005.

[35] F. Giorgi, N. S. Diffenbaugh, X. J. Gao et al., "The regional climate change hyper-matrix framework," Eos, vol. 89, no. 45, pp. 445-446, 2008.

[36] C. Tebaldi and R. Knutti, "The use of the multi-model ensemble in probabilistic climate projections," Philosophical Transactions of the Royal Society A, vol. 365, no. 1857, pp. 2053-2075, 2007.

[37] F. Giorgi, "Uncertainties in climate change projections, from the global to the regional scale," EPJ Web of Conferences, vol. 9, pp. 115-129, 2010.
[38] F. Giorgi and E. Coppola, "Does the model regional bias affect the projected regional climate change? An analysis of global model projections: a letter," Climatic Change, vol. 100, no. 3, pp. 787-795, 2010.

[39] J. S. Pal, F. Giorgi, X. Bi et al., "The ICTP RegCM3 and RegCNET: regional climate modeling for the developing world," Bulletin of the American Meteorology Society, vol. 88, pp. 1395-1409, 2007.

[40] D. Jacob, U. Andræ, G. Elgered et al., “A comprehensive model inter-comparison study investigating the water budget during the BALTEX-PIDCAP period," Meteorology and Atmospheric Physics, vol. 77, no. 1-4, pp. 19-43, 2001.

[41] E. Kjellström, L. Bärring, S. Gollvik et al., "A 140-year simulation of European climate with the new version of the Rossby Centre regional atmospheric climate model (RCA3)," Reports Meteorology and Climatology 108, SMHI, SE-60176, Norrköping, Sweden, 2005.

[42] R. G. Jones, M. Noguer, and D. C. Hassell, Generating high resolution regional climate change using PRECIS, Met Office Hadley Centre, Exter, UK, 2004.

[43] G. Roeckner, L. Bäuml, and R. Bonaventura, "The Atmospheric general circulation model ECHAM5. Part I: model description,” Tech. Rep. 349, Max Planck-Institut für Meteorologie, Hamburg, Germany, 2003.

[44] M. Collins, B. B. B. Booth, G. R. Harris, J. M. Murphy, D. M. H. Sexton, and M. J. Webb, "Towards quantifying uncertainty in transient climate change," Climate Dynamics, vol. 27, no. 2-3, pp. 127-147, 2006.

[45] J. L. Redelsperger, C. D. Thorncroft, A. Diedhiou, T. Lebel, D. J. Parker, and J. Polcher, "African Monsoon Multidisciplinary Analysis: an international research project and field campaign," Bulletin of the American Meteorological Society, vol. 87, no. 12, pp. 1739-1746, 2006.

[46] Van der Linden and J. F. B. Mitchell, ENSEMBLES: Climate Change and its impact: Summary of Research and the Results from the ENSEMBLES Project, Met Office Hadley Centre, Exeter, UK, 2009.

[47] M. B. Sylla, A. T. Gaye, J. S. Pal, G. S. Jenkins, and X. Q. Bi, "High-resolution simulations of West African climate using regional climate model (RegCM3) with different lateral boundary conditions," Theoretical and Applied Climatology, vol. 98, no. 3-4, pp. 293-314, 2009.

[48] R. F. Adler, G. J. Huffman, A. Chang et al., "The version2 global precipitation climatology project (GPCP) monthly precipitation analysis (1979-present)," Journal of Hydrometeorology, vol. 4, no. 6, pp. 1147-1167, 2003.

[49] D. Mitchell, T. R. Carter, P. D. Jones, M. Hulme, and M. New, "A comprehensive set of high-resolution grids of monthly climate for Europe and the globe: the observed record (19012000) and 16 scenarios (2001-2100)," Tyndall Centre for Climate Change Research, Norwich, UK, Working Paper 55, 2004.

[50] P. Xie and P. A. Arkin, "Global precipitation: A 17-year monthly analysis based on gauge observations, satellite estimates, and numerical model outputs," Bulletin of the American Meteorological Society, vol. 78, no. 11, pp. 2539-2558, 1997.

[51] B. Rudolf, C. Beck, J. Grieser, and U. Schneider, "Global Precipitation Analysis Products. Global Precipitation Climatology Centre (GPCC), DWD," Internet publication, pp. 1-8, 2005.

[52] S. M. Uppala, P. W. Kållberg, A. J. Simmons et al., "The ERA40 re-analysis," Quarterly Journal of the Royal Meteorological Society, vol. 131, no. 612, pp. 2961-3012, 2005. 
[53] M. Kanamitsu, W. Ebisuzaki, J. Woollen et al., "NCEP-DOE AMIP-II reanalysis (R-2)," Bulletin of the American Meteorological Society, vol. 83, no. 11, pp. 1631-1643, 2002.

[54] S. Simmons, D. D. Uppala, and S. Kobayashi, "ERA-interim: new ECMWF reanalysis products from 1989 onwards," ECMWF Newsletter, vol. 110, pp. 29-35, 2007.

[55] S. M. Uppala, D. Dee, S. Kobayashi, P. Berrisford, and A. Simmons, "Towards a climate data assimilation system: status update of ERA-interim," ECMWF Newsletter, vol. 115, pp. 12-18, 2008.

[56] K. E. Trenberth, D. P. Stepaniak, J. W. Hurrell, and M. Fiorino, "Quality of reanalyses in the tropics," Journal of Climate, vol. 14, no. 7, pp. 1499-1510, 2001.

[57] A. Diongue, J. P. Lafore, J. L. Redelsperger, and R. Roca, "Numerical study of a Sahelian synoptic weather system: initiation and mature stages of convection and its interactions with the large-scale dynamics," Quarterly Journal of the Royal Meteorological Society, vol. 128, no. 584, pp. 1899-1928, 2002.

[58] Z. Pan, J. H. Christensen, R. W. Arritt, W. J. Gutowski, E. S. Takle, and F. Otieno, "Evaluation of uncertainties in regional climate change simulations," Journal of Geophysical Research $D$, vol. 106, no. 16, pp. 17735-17751, 2001.

[59] M. Ashfaq, C. B. Skinner, and N. S. Diffenbaugh, "Influence of SST biases on future climate change projections," Climate Dynamics, vol. 36, no. 7, pp. 1303-1319, 2011.

[60] F. Giorgi, C. Jones, and G. Asrar, "Addressing climate information needs at the regional level: the CORDEX framework," World Meteorological Organization (WMO) Bulletin, vol. 58, pp. 175-183, 2009.

[61] M. Biasutti and A. H. Sobel, "Delayed Sahel rainfall and global seasonal cycle in a warmer climate," Geophysical Research Letters, vol. 36, no. 23, Article ID L23707, 2009. 

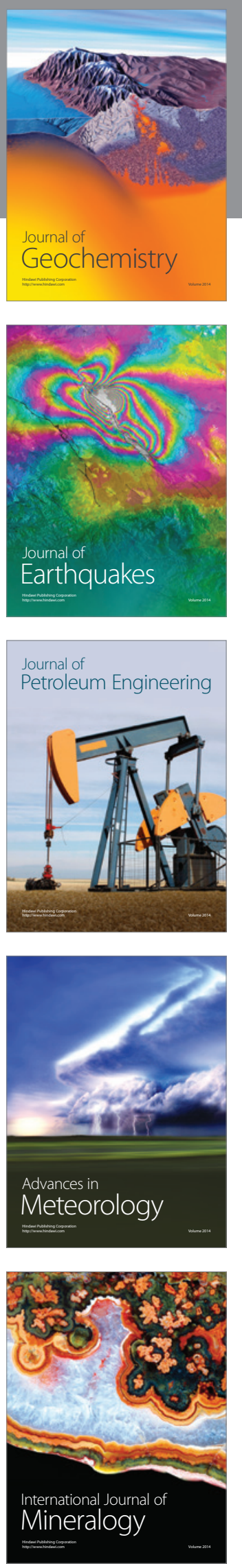
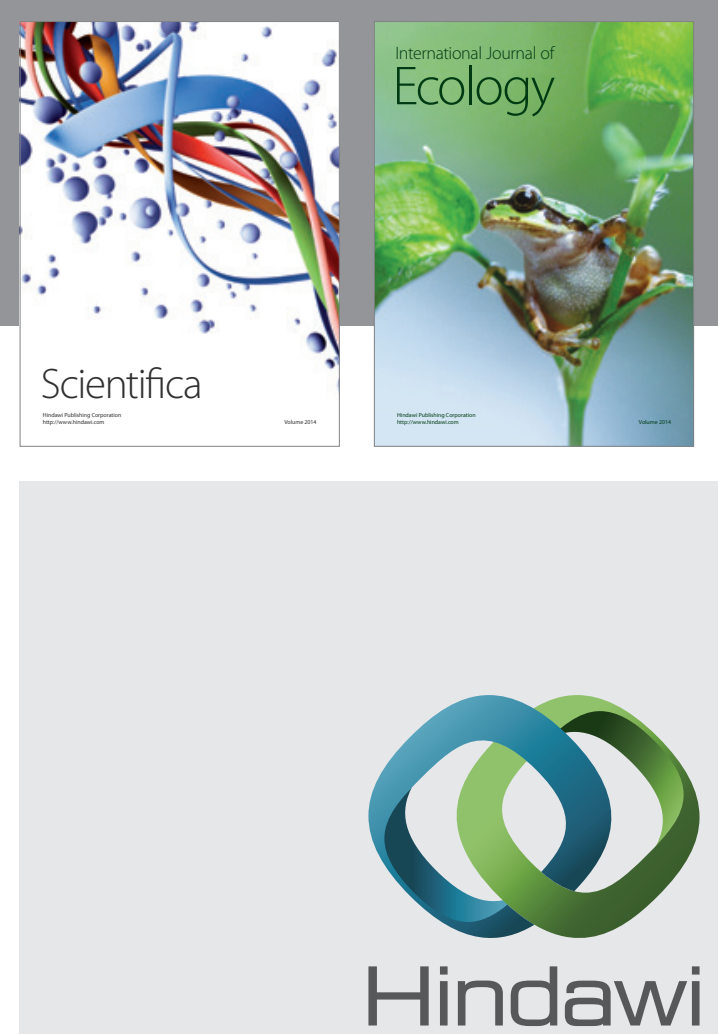

Submit your manuscripts at http://www.hindawi.com
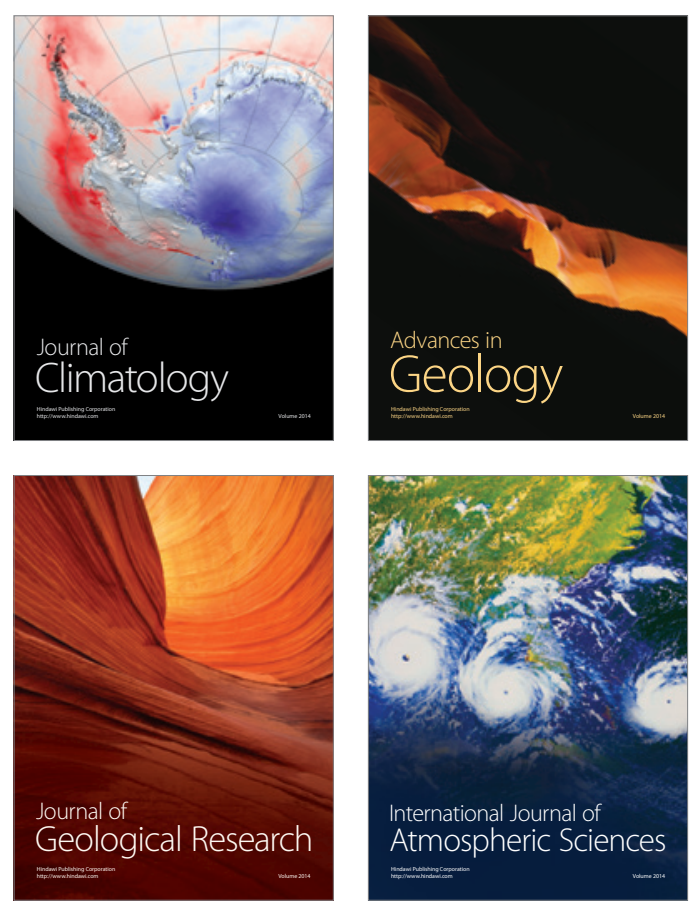
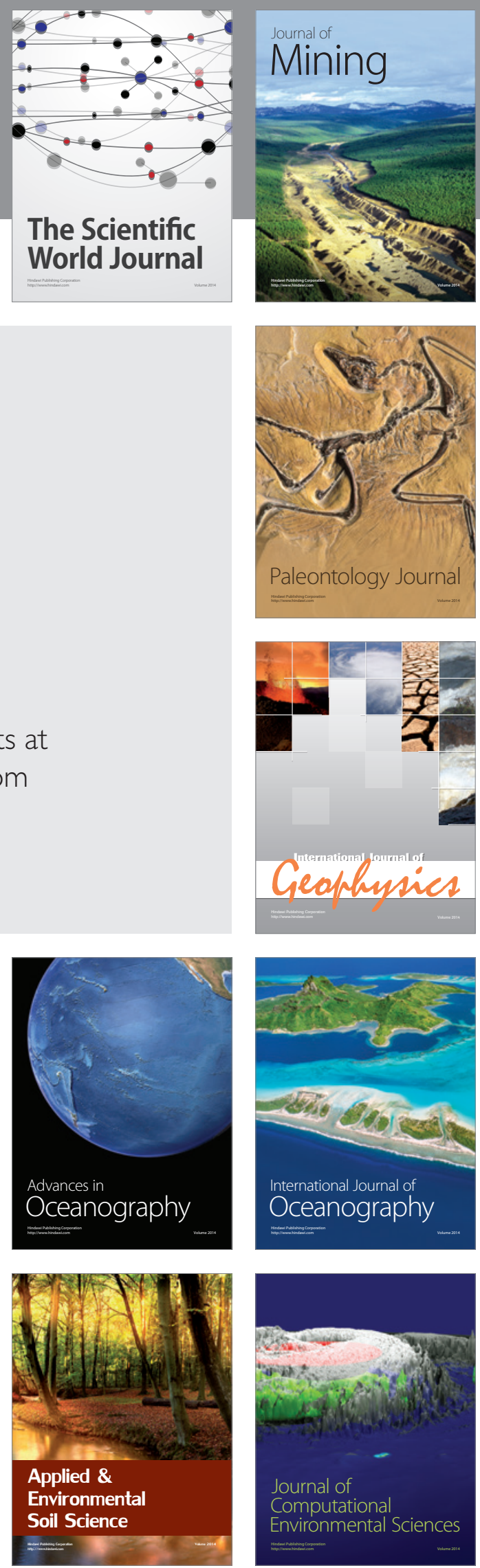